María Cristina Cardona R.

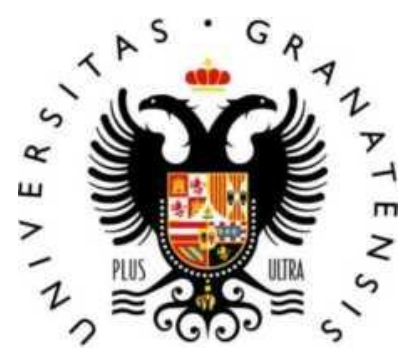

\title{
ADAPTACIÓN DE TAREAS PARA DETECTAR EL TALENTO MATEMÁTICO EN PERSONAS CON DISCAPACIDAD VISUAL BASADA EN EL ANÁLISIS DEL SENTIDO ESPACIAL Y LA GENERALIZACIÓN
}

Presentado por María Cristina Cardona Rendón

Dirigido por

D. Rafael Ramírez Uclés y Dña. María C. Cañadas Santiago.

Granada, 2021 
María Cristina Cardona R.

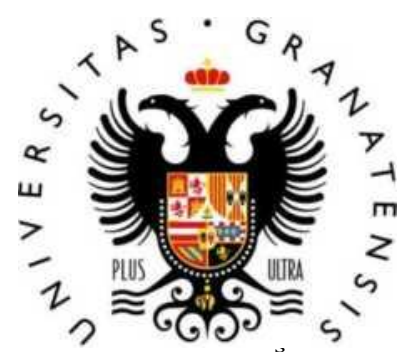

\section{ADAPTACIÓN DE TAREAS PARA DETECTAR EL TALENTO MATEMÁTICO EN PERSONAS CON DISCAPACIDAD VISUAL BASADA EN EL ANÁLISIS DEL SENTIDO ESPACIAL Y LA GENERALIZACIÓN}

Trabajo de Fin de Máster presentado por Dña. María Cristina Cardona Rendón para la obtención del título Máster en Didáctica de la Matemática

\section{MCCR \\ María Cristina Cardona R.}

Tutores

D. Rafael Ramírez Uclés

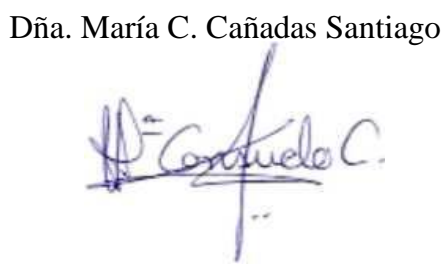

Granada, 2021 


\section{María Cristina Cardona R.}

El presente trabajo de investigación se ha realizado dentro del proyecto de investigación del Plan Nacional I+D con referencias EDU2016-75771-P, financiado por el Ministerio de Economía y Competitividad de España; y en el seno del grupo de investigación "Didáctica de la Matemática. Pensamiento Numérico" (FQM-193) de la Universidad de Granada, perteneciente al Plan Andaluz de Investigación, Desarrollo e Innovación de la Junta de Andalucía. 


\title{
María Cristina Cardona R.
}

\section{Resumen}

En este trabajo se analiza el sentido espacial y la generalización en la resolución de dos tareas propuestas para la identificación del talento matemático por una persona ciega. A partir de este análisis, establecemos algunas pautas para adaptar las tareas y se contrastan con las habilidades requeridas en la prueba original, especialmente en las relativas a las características del talento asociadas a la generalización. Se evidencia que las personas con discapacidad visual requieren la manifestación de otras habilidades, como por ejemplo la memoria visual y la percepción de las relaciones espaciales que no son imprescindibles en el planteamiento para una persona vidente.

\begin{abstract}
In this work, the spatial sense and generalization in the resolution by a blind person of two tasks proposed for the identification of mathematical talent are analyzed. Based on this analysis, some guidelines are established to adapt the tasks and they are contrasted with the skills required in the original test, especially those related to the characteristics of talent associated with generalization. It is evident that people with visual impairment require the manifestation of other skills, such as visual memory and the perception of spatial relationships that are not essential for a sight person.
\end{abstract}


María Cristina Cardona R.

\section{Agradecimientos}

Agradezco en primer lugar a mis tutores, Rafael Ramírez y María Cañadas por su guía, su infinita paciencia y comprensión durante la realización de este trabajo. De manera particular a María Cañadas por su amabilidad, acompañamiento y disposición durante la realización del máster que me hicieron afrontar el proceso de una manera tan cómoda y satisfactoria. ¡Gracias María!

A Laura Marcela Jaramillo de la Universidad de Antioquia, Colombia, por su apoyo incondicional durante todo el proceso académico y mostrarme su disposición infinita aún en la distancia. A ella mis sinceros agradecimientos.

A la familia española que me acogió como una más de los suyos y me brindó su apoyo y escucha siempre que lo necesité. Maricarmen, Joshua y Moisés, a ustedes gracias infinitas. Finalmente, agradezco a mis compañeros presenciales del máster por su disposición de ayudar siempre y el buen compañerismo.

De manera especial a Maite Gutiérrez y Reinaldo Zumarán por la complicidad y todo lo compartido en conocimientos y vivencias. 
María Cristina Cardona R.

\section{ÍNDICE}

Resumen 4

1. JUSTIFICACIÓN Y PLANTEAMIENTO DEL PROBLEMA 1

2. Marco conceptual 4

2.1. Discapacidad visual 4

2.2. Talento matemático $\quad 7$

2.3. Generalización $\quad 8$

2.4. Sentido espacial $\quad 9$

2.5. Objetivos de investigación 12

3. ANTECEDENTES 12

3.1. Sentido espacial 14

3.2. Generalización 16

3.3. Talento y discapacidad visual 18

3.4. Adaptación de material: percepción háptica de las matemáticas y visualización $\quad 22$

4. METODOLOGÍA 25

4.1. Sujetos $\quad 26$

4.2. Características del talento matemático 27

$\begin{array}{ll}\text { 4.3. Instrumento } & 28\end{array}$

4.4. Categorías de análisis 34

5. RESULTADOS 37

5.1. Análisis del sentido espacial y generalización por la participante con $\begin{array}{ll}\text { discapacidad visual } & 37\end{array}$

5.2. Adaptación de las pruebas $\quad 46$

6. CONCLUSIONES 49

6.1. Logro de objetivos de investigación 49

6.2. Limitaciones del estudio y vías de continuidad 53

7. REFERENCIAS 55

8. ANEXOS 62

\section{INDICE DE TABLAS}

Tabla 1. Características del talento matemático..........................................27 


\section{INDICE DE FIGURAS}

Figura 1. Tarea Sembrando Semillas (versión original) ........................................... 30

Figura 2. Tarea 2 Pintando cubos y cubitos (versión original) .................................... 45

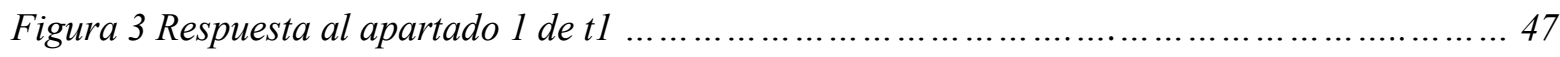

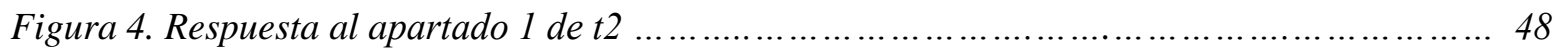

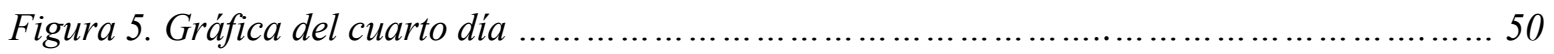

Figura 6. Gráfica del quinto día ............................................................... 51

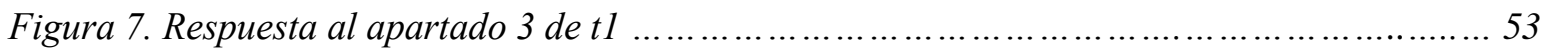

Figura 8. Respuesta al apartado 4 de $t 1$........................................................... 55

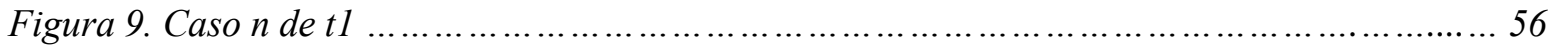

Figura 10. Pregunta 11, Nivel 1, OBMEP. Fuente. Viginheski, et al. (2016), p. 9 .................. 68

Figura 11. Adaptación pregunta 11, Nivel 1, OBMEP. Fuente. Viginheski, et al. (2016), p. 9.......69

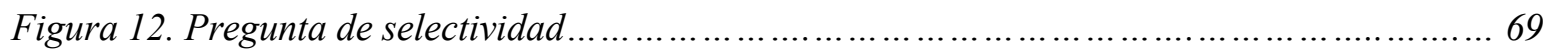

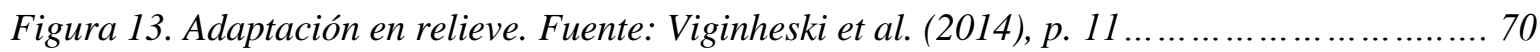





\section{JUSTIFICACIÓN Y PLANTEAMIENTO DEL PROBLEMA}

Este trabajo de investigación viene motivado por el interés y la importancia de caracterizar la detección del talento matemático en estudiantes ciegos. Partimos de la idea de que la ceguera no es un impedimento para el estudio o entendimiento de las matemáticas; únicamente supone una vía de acceso diferente a la información. Además, los estudiantes con discapacidad visual y talento matemático presentan una doble condición de necesidades educativas especiales, que debe ser detectada a tiempo para que los estudiantes sean educados de acuerdo con su capacidad y cualidades. Esto les permitirá desarrollar su potencial y posteriormente contribuir al desarrollo de la sociedad.

Este interés viene motivado desde los aspectos investigativo, curricular y personal. Desde la investigación, encontramos que una de las constantes en los estudios realizados sobre Educación Matemática dirigida a personas con discapacidad visual es la denuncia de la falta de investigaciones al respecto. Esto se evidencia en investigaciones en las que se realizan revisiones bibliográficas, en las que se reporta la baja afluencia de artículos científicos que hay en esta disciplina para este colectivo (Borges et al., 2018; Klingenberg et al., 2019; Llamazares et al., 2019). Concretamente, Klingenberg et al. (2019) encontraron que las investigaciones en Educación Matemática en estudiantes con discapacidad visual no solo son escasas, sino que además son desactualizadas, lo cual contribuye de manera negativa en el impacto de mejora y comprensión de las intervenciones educativas hacia estos estudiantes. Adicionalmente, resulta difícil clasificarlas en categorías para hacer un análisis sistemático ya que no hay una línea continua de investigación, encontrando una gran diversidad de objetivos, métodos y muestras. En este sentido, los autores subrayan la importancia de seguir realizando investigaciones relacionadas con la Educación Matemática y la discapacidad visual, de cara al entendimiento de sus procesos cognitivos en el área y el mejoramiento de las prácticas educativas. 
Esta escasez de investigaciones se agrava al hablar de talento matemático y discapacidad visual en conjunto, tal y como se puede evidenciar en la búsqueda bibliográfica que realizamos y que se detallará más adelante. En esta búsqueda solo recuperamos tres artículos que tratan el tema de la doble excepcionalidad (personas con discapacidad visual y superdotados) pero ninguno de ellos se centra específicamente en el talento matemático. Estos tres artículos tienen en común la denuncia de escasez de investigaciones y la necesidad de centrar la atención en el tema, desarrollando nuevas investigaciones que le apuesten al reconocimiento de la doble excepcionalidad, con la intención de mejorar los servicios especializados que requiere dicha condición (Lopes y Gil, 2016; Rangni y Costa, 2016; Starr, 2003).

Starr (2003) expone además que el interés por estudiar el talento matemático en personas con discapacidad visual viene desde la década de los 70 , cuando incluso se establecieron programas educativos en universidades y centros de investigación de Estados Unidos con los que se buscaba dar respuesta a las necesidades específicas de estudiantes ciegos superdotados. Asimismo, expone que el foco suele centrarse en la discapacidad que posee el estudiante y por tanto no se suelen considerar como estudiantes potencialmente talentosos, lo que hace que su identificación sea aún más difícil.

Desde el punto de vista curricular, es importante mencionar que la atención a los estudiantes con necesidades educativas especiales (NEE) es una demanda constante que se evidencia en los documentos curriculares de diferentes países, e incluso por parte de organismos internacionales implicados en la educación tales como el National Council of Teachers of Mathematics (2000), la OCDE (2005) y la UNESCO, quien en la declaración de Salamanca (1994) recoge que todos los niños tienen derecho a la educación, independientemente de sus dificultades o necesidades especiales, entendiendo que cada uno posee unas características únicas e idiosincráticas que conllevan a su vez unos intereses, habilidades o necesidades peculiares que deben ser debidamente atendidos en la escuela. Esto se traduce en un reto de mayores proporciones cuando hablamos de alumnos con una doble condición de NEE, el cual es un tema de gran interés como se puede ver en documentos internacionales tales como el "Handbook of Gifted Education" (2008). 
Esta escasez generalizada de investigaciones puesta de manifiesto por diversos autores y plasmada de una manera evidente en las búsquedas bibliográficas realizadas, convoca a seguir con una línea de trabajo que empieza a ser explorada, especialmente cuando a nivel curricular se exige una metodología y recursos específicos que den respuesta a las necesidades educativas especiales que tienen estos alumnos (Ley General de Educación 115, Colombia, 1994), de manera que el respeto por la diversidad y la especificidad de cada individuo se convierta en un principio básico de toda enseñanza, donde no se limite el pleno desarrollo personal de los niños (Delors et al., 1996).

Finalmente, hay una motivación extra de índole personal por la cual quise realizar esta investigación. Yo, como estudiante con discapacidad visual (ceguera) de la licenciatura en matemáticas he constatado a lo largo de mi experiencia escolar y universitaria que las barreras que encontramos para su estudio provienen del entorno educativo. Una de estas barreras la encontré precisamente al participar en las olimpiadas de matemáticas. Esta es una estrategia académica y de movilización social para el mejoramiento de la calidad educativa aplicada por la secretaría de educación de Medellín, Colombia. Para ello, los estudiantes de las instituciones que deciden participar en dicho proceso deben realizar una serie de pruebas en las que se evalúan los conocimientos adquiridos en matemáticas hasta el nivel escolar $\left(5^{\circ} \mathrm{de}\right.$ primaria o $9^{\circ}$ de educación secundaria colombiana, 10-11 y 14-15 años respectivamente) que se está cursando en el momento de presentarla. Al no contar con ninguna adaptación, la realización de estas pruebas por parte de las personas con discapacidad visual debía ser asistida por un lector que muchas veces no tenía el conocimiento necesario para poder realizar la lectura. Esto hizo imposible la participación en igualdad de condiciones, lo que no solo implica un estancamiento en el proceso académico y educativo del estudiante ciego, sino una desmotivación del mismo. Al respecto los autores Viginheski et al. (2014a) señalan la importancia de una correcta adaptación en las pruebas para que el estudiante ciego no quede en desventaja con respecto a sus compañeros videntes. La no adaptación o realizar una adaptación inadecuada, puede convertirse en un obstáculo no solo para el acercamiento al contenido matemático sino para la evaluación del mismo. 
En este sentido, y en cumplimiento de las directrices generadas por los diferentes organismos citados, en este trabajo nos proponemos estudiar dos aspectos matemáticos en relación con la discapacidad visual para determinar qué tipo de adaptaciones, dificultades y/o ventajas pueden existir para su identificación:

Por un lado la generalización, entendiendo que representa una de las características más importantes asociadas al talento matemático (Freiman, 2006; Greenes, 1981; Krutetskii, 1976; Miller, 1990), y por otro el sentido espacial y habilidades de visualización, con respecto a lo cual no hay un consenso, pues algunos autores (Gruessing, 2011; Rabab`h y Veloo, 2015; Rivera, 2011; Van Garderen, 2006; Van Garderen y Montague, 2003) postulan que no hacen parte de las características del talento matemático; mientras que otros autores (Krutetskii, 1976; Lee et al., 2007; Neria y Amit, 2010; Presmeg, 1986; Ramírez, 2012; Ryu et al., 2007) defienden que sí son aspectos relevantes en la caracterización del talento. No obstante, hemos decidido estudiar tanto el sentido espacial como la visualización, pues al tratarse de aspectos en principio asociados a la visión, suscitan un interés investigativo especial al relacionarse con la discapacidad visual.

Para lograr lo anterior el trabajo estará dirigido a responder a las siguientes preguntas que han motivado esta investigación: ¿qué influencia tiene la discapacidad visual en la manifestación de características asociadas al talento matemático (generalización) y en la manifestación del sentido espacial y particularmente, en las habilidades de visualización?, ¿qué características del talento matemático manifiesta una persona con discapacidad visual? y ¿cómo se debe adaptar una prueba de diagnóstico del talento matemático para que pueda ser resuelta de manera satisfactoria por un estudiante con discapacidad visual?

\section{MARCO CONCEPTUAL}

\subsection{Discapacidad visual}

El concepto de discapacidad es un concepto que ha ido evolucionando a través de la historia, afectado por las diferentes dinámicas sociales de cada momento histórico. Por un lado, tenemos el modelo médico, donde se asume la discapacidad desde un punto de vista meramente 
científico y es considerada como una enfermedad. Por otro lado, el modelo social, donde se pasa a un enfoque de derechos y por tanto la discapacidad no se considera un atributo de la persona, sino el resultado de las relaciones sociales, reconociendo que las personas con discapacidad pueden contribuir a la sociedad en la medida en que sean incluidas y aceptadas socialmente (Hernández, 2015). Actualmente, se aboga por un modelo que integre ambas concepciones, donde se reconozca la restricción que proviene del entorno pero sin desconocer la limitación que proviene de la misma deficiencia física, sensorial o mental. En este sentido Ripollés (2008), señala que la discapacidad es un concepto global genérico y no debe entenderse como la consecuencia de la enfermedad, sino que en ella se recogen las deficiencias en las funciones y estructuras corporales, las limitaciones en la capacidad de llevar a cabo actividades y las restricciones en la participación social del ser humano. En el preámbulo de la convención de los derechos de las personas con discapacidad (ONU, 2007) se afirma que la discapacidad “(...) es un concepto que evoluciona y que resulta de la interacción entre las personas con deficiencias y las barreras debidas a la actitud y al entorno que evitan su participación plena y efectiva en la sociedad, en igualdad de condiciones con las demás” (p. 1). Es decir que la discapacidad no está en la persona que tiene una limitación, sino en la relación que tiene esta persona con el entorno que puede ponerle barreras arquitectónicas, sociales, entre otras, excluyendo su participación efectiva, o por el contrario, aceptarla y brindarle los ajustes necesarios para que pueda desenvolverse funcionalmente dentro de su medio físico y social (Muñoz, 2010).

En particular, se dice que la discapacidad visual se presenta cuando hay una deficiencia funcional en el órgano de la visión y de las estructuras y funciones asociadas (OMS, 2013). Está determinada por los niveles de deterioro de la función visual, que viene dada por la pérdida o disminución de la agudeza visual (capacidad para discriminar objetos y figuras con la distancia) y del campo visual (espacio que los ojos abarcan mirando a un punto fijo) de cada uno de los ojos por separado, o la ausencia total de ambos. Según la OMS (2012) la discapacidad visual puede subdividirse en moderada o grave (normalmente agrupadas en lo que se denomina baja visión) y ceguera. La baja visión se refiere a una percepción visual disminuida o insuficiente, la cual, a pesar de las ayudas ópticas que el estudiante pueda 
utilizar, sigue estando bajo el promedio de una visión normal; mientras que la ceguera se refiere a una pérdida total de la visión, o bien que la poca que se posea sea sea tan reducida que no permita desarrollar actividades utilizando esta vía de percepción (Pérez-Ruiz, S.F). Este último caso será el que abordemos en este trabajo. Además, es importante señalar que las dificultades visuales pueden producirse antes del nacimiento (congénitas) o posterior a él (adquiridas). Esto último implica que la persona, previo a la condición de ceguera, percibió colores, formas, tamaños, etc. Lo que puede cambiar su manera de percibir y relacionarse con el mundo, en muchas ocasiones favoreciendo su autonomía y aprendizaje. Esto a su vez puede significar una ventaja en el acercamiento a los objetos matemáticos en particular y su posterior evaluación (Fernández, 1995). De hecho, según Pérez-Ruiz (S.F) uno de los problemas que enfrentan las personas con ceguera es el conocimiento del espacio que les rodea, así como el movimiento y la orientación en el entorno. Y puntualiza:

Efectivamente, cuando falta la visión resulta difícil recoger, procesar, almacenar y recuperar aquella información de tipo figurativo o espacial. Las características de las modalidades sensoriales que el niño con ceguera ha de utilizar para sustituir la visión hacen más difícil y costosa la recogida de información sobre las características espaciales del ambiente. (p. 5)

Lo anterior implica que la persona ciega puede presentar un retraso con respecto a la persona con visión normal en aquellos aspectos de su desarrollo cognitivo más relacionados con problemas figurativos y espaciales, más aún si tenemos en cuenta que el $80 \%$ de la información que se obtiene del entorno se hace a través de la visión. Al acceder al mundo que les rodea con los otros sentidos, la construcción de su aprendizaje puede presentar ciertas particularidades. No obstante, la mayor parte de las investigaciones realizadas en los últimos años sobre el desarrollo cognoscitivo de estos estudiantes ponen de manifiesto que, al llegar a la adolescencia y la edad adulta, pueden alcanzar un desarrollo funcionalmente equivalente a las personas que ven (Pérez-Ruiz, S.F). Por último, reiterar que no es posible establecer un perfil específico o único para el desarrollo de las personas con discapacidad visual, debido a la heterogeneidad determinada por los diversos grados de deficiencia visual y los distintos 
momentos de aparición de la misma, y a las experiencias sociales, familiares o educativas que cada uno haya vivido.

\subsection{Talento matemático}

En la literatura sobre el talento existe una amplia diversidad de términos para referirse a esta condición: superdotados, altas capacidades, alto rendimiento, etc., lo que supone diferentes enfoques a la hora de definirlo y por tanto de identificarlo: Es decir, diferentes instrumentos, heterogeneidad en lo que se considera una persona con talento, entre otros.

Debido a que en este trabajo nos proponemos analizar la influencia de la discapacidad visual en la manifestación de características asociadas al talento matemático, lo que incluye analizar habilidades matemáticas concretas (en este caso particularmente las asociadas al sentido espacial y generalización) nos apoyaremos en la definición planteada por Passow (1993) quien postula que los niños superdotados y talentosos son aquellos que

(...) en virtud de sus habilidades sobresalientes, son capaces de un alto rendimiento. Incluyen aquellos que han demostrado sus logros y/o habilidades potenciales en cualquiera de las siguientes áreas, sea aisladamente o combinadas: 1) habilidad intelectual general, 2) aptitudes académicas específicas, 3 ) pensamiento creativo o productivo, 4) habilidad de liderazgo, 5) artes visuales e interpretativas, 6) habilidades psicomotoras. (p. 30)

Esta definición puede perfilarse y concretarse para el área de las matemáticas si se tienen en cuenta las características propias del talento matemático enunciadas por autores como Greenes (1981), Miller (1990) y Freiman (2006) recogidas en Ramírez (2012). Estos autores proponen un listado de características que, si bien se diferencian en algunos matices, al buscar la interrelación entre ellas podemos concluir que el concepto de talento matemático se define en términos de la superioridad manifestada en algunos procesos matemáticos. Por ejemplo, la abstracción, generalización, discernimiento de estructuras, control de los datos, invertir operaciones matemáticas, pensamiento analógico y heurístico en la toma de decisiones en situaciones de resolución de problemas, visualización de relaciones, entre otros.

Un aspecto muy importante con respecto al talento y en el que nos enfocaremos de manera especial en este trabajo es el relativo a la identificación. Para la identificación de estos alumnos 
se utilizan tanto pruebas subjetivas (informes realizados por profesores, padres, nominaciones de los compañeros, autoinformes, entre otros) como pruebas objetivas que se basan en la aplicación de tests. Este último es el caso de nuestro trabajo, puesto que utilizaremos dos problemas extraídos de una prueba de selección de alumnos con talento matemático en los que se busca reconocer algunas de las características mencionadas anteriormente.

Para profundizar en la identificación de alumnos con talento destacamos el trabajo de Ramírez (2012), quien recoge y profundiza de manera amplia en las diferentes posturas y métodos a seguir. Al igual que el autor, resaltamos lo expuesto por Pitta-Pantazi y Christou (2009), quienes sugieren que los instrumentos creados con este fin deberían medir habilidades como inteligencia general, visualización, razonamiento verbal y no verbal, atención, memoria y respuestas a tareas de resolución de problemas generales. Para el caso específico de las matemáticas, valorar aspectos como el pensamiento lógico, las relaciones cualitativas y espaciales, la flexibilidad y reversibilidad en los procesos mentales, la percepción del mundo desde el punto de vista matemático, la creatividad matemática, y por último las habilidades de percepción y generalización así como el razonamiento analítico, deductivo e inductivo.

\subsection{Generalización}

Como se ha podido observar, distintas características del talento matemático están estrechamente relacionadas con la generalización, la cual abordaremos en este trabajo. La generalización constituye uno de los procesos cognitivos más importantes de la matemática, llegando incluso a ser considerada como el verdadero nervio de la matemática, como esencia del álgebra (Mason et al., 1992), y como elemento clave en la construcción de conocimiento en general y matemático en particular (Piaget, 1975). De hecho, en el NCTM (2003) la generalización se presenta como uno de los principales objetivos de la instrucción matemática. La generalización, de acuerdo con Pólya (1989) es la capacidad para generar nuevos ejemplos a partir de la detección y sistematización de una regularidad en un conjunto de elementos; en términos de Mason (1996) la generalización consiste en “(...) ver una generalidad en lo particular y ver lo particular en lo general” (p. 65). En este trabajo asumiremos la definición de Kaput (1999), 
quien postula que generalizar consiste en extender el razonamiento más allá de los casos considerados, bien identificando y expresando la similitud encontrada o bien desplazando el foco de los casos para ampliar el razonamiento hacia los patrones, procedimientos, estructuras y relaciones entre estos.

Un aspecto esencial en la habilidad para generalizar es el reconocimiento de patrones (Castro et al., 2010). Esto implica la identificación de una regularidad que conlleve al establecimiento de un patrón que sea válido para otros casos. Al respecto Radford (2008) establece que la generalización de patrones implica la identificación de una propiedad común, generalizar dicha propiedad a todos los términos de la secuencia y usarla para encontrar una regla que permita calcular cualquier término de la secuencia. Las tareas de generalización pueden incluir patrones en los que hay que buscar relaciones numéricas, disposición de elementos en el plano o bien de percepción visual y espacial (Castro et al., 2010). Castro y Cañadas (2007) ponen de manifiesto que existe una estrecha relación entre la generalización y el razonamiento inductivo, el cual se entiende como la capacidad de extraer una conclusión general que agrupe las características de unos datos particulares que previamente fueron observados. Estas autoras plantean un modelo de siete pasos basado en los trabajos de Pólya (1945) y Reid (2002) para describir las etapas del razonamiento inductivo, donde la generalización aparece como la sexta en orden. La describen como un paso imprescindible pero a la vez como uno de los que más cuesta a los estudiantes.

\subsection{Sentido espacial}

Existe una gran diversidad de términos para referirse al concepto de sentido espacial (razonamiento visual, capacidad espacial, pensamiento espacial, percepción espacial, visión espacial, etc.) y cada una de ellas tiene un grado de relación con la visualización, de acuerdo con los elementos visualizadores que recoge. Por ejemplo, Lean y Clements (1981) se refieren a la habilidad espacial como la habilidad para crear y manipular imágenes mentales. En esta misma línea aparece la definición enunciada por el NCTM (1989) donde el sentido espacial se define como un sentimiento intuitivo del entorno y los objetos que hay en él. Por su parte Del Grande (1987) lo define como percepción espacial y postula que se trata de la habilidad 
para reconocer y discriminar estímulos en y desde el espacio, interpretándolos y relacionándolos con experiencias previas.

Bishop (1983) enfatiza la visualización, aludiendo a un sentido intuitivo para relacionar la forma y el espacio. Este sentido implica la habilidad para reconocer, visualizar, representar y transformar formas geométricas, así como otras formas de observar el espacio de dos o tres dimensiones. Por ejemplo el doblado de papel, transformaciones, teselaciones y proyecciones. En esta misma línea Human (1998) enuncia diferentes formas de interacción con el espacio: observar objetos y sus propiedades (cambios de posición, forma, relación, tamaño), generar información que puede ser observada directamente (determinar distancias, elevaciones, áreas y volúmenes) y representar e interpretar objetos espaciales en dos dimensiones.

En este trabajo entenderemos el sentido espacial en términos de la operativización presentada por Flores et al. (2015) quienes postulan el sentido espacial como "un modo intuitivo de entender el plano y el espacio para identificar cuerpos, formas y sus representaciones, que implica manejar relaciones y conceptos de geometría de forma no convencional, incluyendo la habilidad para reconocer, visualizar, representar y transformar formas geométricas” (p. 129) y que a su vez, conforma una nueva dimensión de pensamiento que nos servirá para interactuar con el entorno y crear representaciones mentales del mismo. Escogemos esta definición puesto que engloba aspectos de visualización y elementos geométricos, además de que nos permite operativizarlo para el análisis de los resultados. Por esto, recogemos las componentes básicas que definen para el sentido espacial:

- Elementos geométricos: Conocer propiedades de las formas y las figuras que permiten su identificación, ordenación y clasificación. Incluye identificarlas a través del nombre, la definición y diversas representaciones.

- Relaciones geométricas: Apreciar cualidades en las formas y en los cuerpos geométricos como la simetría, congruencia, equivalencia, igualdad, etc.

- Ubicación y movimientos: Disponer de referentes para describir posiciones en el plano o en el espacio, llevar a cabo movimientos y reconocer en ellos regularidades o elementos invariantes. 
Hay una cuarta componente que es trasversal a las tres anteriores y es la visualización. Al respecto destacamos el trabajo de Gutiérrez (1996), quien sintetiza las diferentes concepciones sobre percepción visual encontrando cuatro elementos básicos presentes en todas ellas: imágenes mentales, que hacen referencia a las representaciones mentales que nos hacemos sobre objetos físicos, relaciones, conceptos, etc.; representaciones externas, que se refieren a las representaciones verbales o gráficas de conceptos o propiedades que ayudan a crear o transformar imágenes mentales y a hacer razonamiento visual; los procesos, en los que las imágenes visuales se manipulan en la actividad de visualización; y finalmente las habilidades, referidas a la capacidad para crear y procesar imágenes visuales. De estos cuatro elementos, en nuestra investigación pondremos el foco sobre las habilidades, ya que las consideramos relevantes en relación a los procesos de resolución de las personas ciegas. Las habilidades incluyen, además de lo relativo al sentido espacial, capacidades para "representar, transformar, generar, comunicar, documentar y reflejar información visual” (Hershkouitz, 1990). En este trabajo nos acogemos a las siete habilidades recopiladas por Del Grande (1990) basado en Hoffer (1977), pues también nos permiten un análisis operativo de nuestros datos, centrándonos en determinar la manifestación de estas habilidades:

- Coordinación visomotora: Habilidad para seguir con los ojos el movimiento de los objetos de forma ágil y eficaz.

- Percepción figura-contexto: Habilidad para reconocer una figura aislándola de su contexto, en el que aparece camuflada o distorsionada por la superposición de otros elementos gráficos.

- Conservación de la percepción: Habilidad para reconocer que un objeto mantiene su forma, aunque cambie de posición o deje de verse total o parcialmente.

- Percepción de la posición en el espacio: Habilidad del observador para relacionar su propia posición (o la de un objeto que actúa como punto de referencia) con la de otro objeto. Incluye la percepción de inversiones y giros de figuras. 
- Percepción de las relaciones espaciales: Habilidad que permite identificar correctamente las relaciones internas entre diversos objetos situados simultáneamente en el espacio.

- Discriminación visual: Habilidad que permite comparar varios objetos identificando sus semejanzas y diferencias visuales, independientemente de su posición.

- Memoria visual: Habilidad para recordar las características visuales y de posición que tenían en un momento dado un conjunto de objetos que estaban a la vista pero que ya no se ven o que han sido cambiados de posición.

\subsection{Objetivos de investigación}

Con el fin de dar respuesta a las inquietudes planteadas en el capítulo de justificación, se proponen los siguientes objetivos bajo los cuales se orientará y definirá la investigación:

Objetivo general

Analizar la influencia de la discapacidad visual en la manifestación de características del talento matemático, generalización y componentes del sentido espacial y visualización demandadas en dos problemas extraídos de una prueba de detección del talento matemático.

Objetivos específicos

- Analizar la manifestación de habilidades de generalización, sentido espacial y visualización en el proceso de resolución de una persona ciega sobre dos problemas extraídos de una prueba de detección del talento matemático.

- Estudiar y proponer posibles adaptaciones de las pruebas de detección del talento matemático para que puedan ser resueltas por estudiantes ciegos, manteniendo las características demandadas en los problemas.

\section{ANTECEDENTES}

Como mencionábamos anteriormente, tras realizar la búsqueda bibliográfica nos encontramos con una gran escasez en trabajos que aborden conjuntamente el talento matemático y la dis- 
capacidad visual, por lo que en este capítulo recogemos todas aquellas investigaciones relacionadas de manera directa o indirecta que nos sirvan como soporte para dar respuesta a los objetivos planteados.

Debido a que se trata de un estudio exploratorio y teniendo en cuenta la escasa literatura que encontramos al respecto, consideramos de gran importancia describir detalladamente el proceso de búsqueda que se siguió y que nos llevó a obtener estos resultados. La búsqueda fue realizada en diferentes motores de búsqueda y bases de datos como Google Scholar, Funes, scopus, WOS (web of science), ERIC (Education Resources Information Center) y Teseo. Utilizamos las palabras clave "talento matemático" y "discapacidad visual”, siendo esta última remplazada por "ciego" o "invidente" en algunos casos y probando con las diferentes combinaciones tanto en castellano como inglés. En inglés se utilizaron las variaciones "mathematical talent", "giftedness", "high ability" o "high achieving", en sus diferentes combinaciones con "visual impairment" y "blind". Para refinar las búsquedas, tanto en inglés como en castellano, utilizamos el operador booleano "and", y en los casos que fue necesario el operador de truncamiento “*” como sufijo con el fin de encontrar todos los términos que comenzaran con las letras precedentes.

Así, por ejemplo, al buscar en WOS "gift* and visual impairment" se obtuvieron 29 resultados. Una vez leídos los resúmenes pudimos constatar que solo dos de ellos estaban de alguna manera relacionados con el talento matemático en personas con discapacidad visual, al tratar sobre niños ciegos superdotados. No obstante, se sigue echando en falta el componente específico del talento matemático. Al sustituir "visual impairment" por "blind" se obtuvieron 170 resultados, de los cuales no se ajustó ninguno. No encontramos en estos artículos referencias al talento matemático en personas ciegas desde ninguno de sus aspectos, es decir tratamiento, identificación, etc. Al buscar en scopus con "gift* and visual impairment" se obtuvieron 26 resultados, encontrando un artículo relacionado en el que se analiza el desempeño de personas ciegas en una prueba estandarizada. Algunos de los resultados encontrados en Google Scholar se repitieron en estas bases de datos así como los que aparecían en cada una, lo que ayudó en la depuración de los artículos. También es importante destacar 
que con estas búsquedas se encontraron tanto artículos en inglés como en español, por lo que no fue necesario emplear los términos en español para una nueva búsqueda.

En el repositorio digital de documentos en Educación Matemática FUNES, al buscar "discapacidad visual and talento matemático" solo se obtuvieron 13 resultados, de los cuales no tenía ninguno relación con el tema. Al variar discapacidad visual por invidente o ciego se obtuvieron dos y siete resultados respectivamente. Sin embargo, tampoco encontramos artículos relacionados con el tema, solo algunos relacionados de manera indirecta. Esto es, que tratan sobre los procesos de enseñanza y aprendizaje de las matemáticas a estudiantes con discapacidad visual, pero ninguno se ocupa del talento matemático. Asimismo, es importante destacar que se hizo una revisión de las últimas dos actas de congresos sobre educación matemática, por considerar que las de ese período podrían no estar incluidas en las búsquedas realizadas en la red, como ICME, PME, CERME y la SEIEM, de las cuales solo se pudieron recuperar cuatro artículos relacionados con la discapacidad visual, aunque no así con talento.

Con este panorama, en este capítulo exponemos toda la información recabada relacionada de manera directa o indirecta con nuestros objetivos de investigación, desde aquellos relacionados con la discapacidad visual y el talento matemático hasta los relacionados con las características evaluadas en los problemas que son nuestro objeto de investigación, tales como la generalización y el sentido espacial.

\subsection{Sentido espacial}

Un estudio que consideramos relevante para nuestro trabajo es el realizado por ThinusBlanc y Gaunet (1997), puesto que explora aspectos relacionados con la visualización en personas ciegas (por ejemplo la manipulación mental de objetos) lo que nos brinda un punto de partida para contrastar con los análisis de nuestros datos. Concretamente, las autoras llevan a cabo una investigación en la que revisan algunos estudios que se han realizado sobre la incidencia de la experiencia visual temprana en el desarrollo de las habilidades espaciales, encontrando datos divergentes con respecto a personas con ceguera temprana: algunos autores reportan déficits importantes, mientras que otros no encuentran evidencias de efectos negativos en el caso de la privación visual temprana. Las autoras destacan el papel 
fundamental que juega la visión en la cognición espacial, puesto que ésta afecta de manera directa la construcción de representaciones espaciales. Desde la percepción háptica las construcciones espaciales también se hacen de manera secuencial, pero con evidentes limitaciones debidas al alcance del tacto que se restringe a lo cercano, mientras lo lejano es desconocido.

No obstante, las autoras hacen referencia a diferentes estudios que se llevaron a cabo comparando los resultados de grupos de personas con los ojos vendados, con ceguera tardía y ceguera temprana. Por ejemplo, para estudiar la rotación mental de objetos, los participantes exploraban el objeto con una mano mientras que en la otra recibían el mismo objeto con diferentes grados de rotación. En este estudio se reportó que las personas con ceguera temprana cometieron muchos más errores de emparejamiento y un aumento considerable en los tiempos de reacción en comparación con los otros dos grupos. En todos estos estudios se utilizaron materiales a los que los participantes podían acceder de manera igualitaria, pero se remarca la diferencia a la hora de que sea la misma persona ciega quien tenga que realizar el dibujo, especialmente en cuanto al tiempo que se tarda. Esto puede convertirse en una desventaja al presentar una prueba de selección como la que escogemos en este trabajo para hacer el análisis de dos de sus problemas, los cuales implican la realización de dibujos en su respuesta.

El estudio de Cornoldi et al. (1991) tiene una estrecha relación con uno de los problemas que son objeto de estudio en nuestra investigación, pues involucra la interacción con objetos de diversa complejidad y compuestos por cubos. Se pidió a los participantes que siguieran caminos imaginarios a través de objetos de diversa complejidad y compuestos de bloques de construcción en forma de cubos ensamblados, basándose en instrucciones dadas verbalmente por el investigador. En esta tarea los participantes con ceguera temprana mostraron habilidades limitadas en comparación con los videntes. Sin embargo, cuando los caminos variaron a tres dimensiones, se encontró el mismo patrón de error en ambos grupos. Los autores postularon al respecto que el déficit de los participantes con ceguera temprana se debió más a una experiencia y práctica limitadas con objetos tridimensionales que a no construir y usar imágenes mentales. Las imágenes mentales pueden ayudar a las personas a recordar 
secuencias complejas de objetos familiares y, por tanto, la diferencia entre videntes y ciegos en tareas espaciales son cuantitativas y dependientes de la memoria más que cualitativas.

Por último, destacamos de manera especial los resultados encontrados por Aznarte (2018), siendo este el trabajo que tomaremos como referencia para el contraste de nuestros resultados. La autora llevó a cabo una investigación en la que analiza las componentes del sentido espacial que se ponen en juego al resolver los dos problemas que son objeto de investigación en este trabajo, y analiza la diferencia que se da entre las dos tareas. Encuentra que en general los estudiantes tienen un mejor desempeño en preguntas que no requieren la activación de las componentes del sentido espacial y las habilidades de visualización, postulando que esta situación se debe al desconocimiento de los estudiantes de determinados contenidos asociados a la percepción visual. En esta investigación también se comparan los resultados globales obtenidos por los alumnos que fueron seleccionados como alumnos con talento matemático y los no seleccionados, encontrando que los seleccionados tienen un mayor rendimiento en las tareas analizadas, siendo notorio de manera particular en los problemas que implican el sentido espacial.

\subsection{Generalización}

Abordamos la generalización en un contexto funcional. Se han realizado investigaciones sobre las dificultades que tienen los estudiantes al generalizar en diferentes cursos (Barbosa et al., 2012; Stacey, 1989), las estrategias y representaciones que emplean (Ureña et al., 2019; Ureña et al., en revisión; Zaskis y Liljedahl, 2002), el papel de lo numérico y lo visual-geométrico en el proceso de generalización y sus diferentes etapas (García-Cruz y Martinón, 1996; Vale, 2010), así como aquellos que se centran en estudiar las estructuras, patrones y relaciones funcionales que identifican los estudiantes (Cañadas et al., 2007; Carraher et al., 2008; Pinto y Cañadas, 2019), todos ellos procesos relativos a la generalización en un contexto funcional. Estos estudios se llevan a cabo con alumnos en los últimos cursos de primaria (11-12 años, generalmente sin formación algebraica), los primeros de secundaria (13-15 años, con cierta formación algebraica) y profesores de primaria o secundaria en formación. En ellos se establecen categorías similares para analizar los resultados relativos a las estrategias que emplean 
(conteo, proporción directa y lineal) y la naturaleza de las representaciones que surgen del trabajo de los estudiantes (numérica, visual y mixta, donde se combinan ambas). A partir de ello, concluyen que los estudiantes de primeros cursos de primaria tienden a utilizar con mayor frecuencia las representaciones numéricas (Cañadas et al, 2007; Ureña et al., 2019), y las dificultades que presentan a la hora de generalizar se deben a un uso erróneo de la proporción directa y la tendencia a pensar de manera recursiva (carraer et al., 2008) lo cual no contribuye a la comprensión de la estructura de un patrón. Desde el punto de vista funcional, las investigaciones han constatado como una de las mayores dificultades a la hora de generalizar el paso del recuento a la abstracción de la regla del patrón (Stacey, 1989; Ureña et al., en revisión) lo que se asocia con la falta de flexibilidad. Lo anterior se traduce también en una mayor facilidad para trabajar con casos particulares y no con los generales, lo que tiene su explicación en la exigencia cognitiva que implica la extensión de los razonamientos y procedimientos.

García-Cruz y Martinón (1996) reportan que el dibujo juega un doble papel en el proceso de abstracción y generalización. Por un lado, representa la vía principal para los estudiantes que utilizan representaciones visuales, coincidiendo con Vale (2010) quien encontró el soporte visual como una ayuda invaluable para comprender la estructura de un patrón. Por otro lado, sirve como método para dar validez a la respuesta encontrada por medio de representaciones numéricas para aquellos que utilizan la mixta, pero que favorecen la numérica. De igual manera y coincidiendo con lo encontrado con respecto al sentido espacial, Barbosa et al. (2012) encontraron que los estudiantes prefieren enfoques analíticos o numéricos, presentando mayores dificultades cuando la tarea tiene un componente visual. Con respecto al trabajo con profesores en formación, Zazkis y Liljedahl (2002) encontraron que al proponer la generalización de un patrón numérico-visual repetitivo, los participantes se dedicaron a detectar similitudes y diferencias, clasificar y etiquetar, buscar algoritmos, conjeturar y argumentar, establecer relaciones numéricas entre componentes. En definitiva, generalizar sobre datos y relaciones matemáticas, todas ellas actividades propias del pensamiento algebraico según Mason (1996) y Kaput (1999).

Destacamos de manera especial el trabajo de Ureña et al. (en revisión). Estos autores analizaron las estrategias y representaciones de generalización que emplearon estudiantes que 
cursaban últimos años de educación primaria y primeros cursos de secundaria (11-13 años) al resolver una de las tareas que son objeto de investigación en nuestro estudio. Resaltan la variedad de estrategias utilizadas al avanzar en la tarea (respuesta directa, conteo, proporcionalidad y correspondencia), reforzando el alcance de esta última para generalizar reportado en otras investigaciones. En cuanto a la expresión de la generalización, reconocen tres representaciones: verbal, simbólica y múltiple. Manifiestan que cuando se trata de casos particulares, los estudiantes priorizaron las representaciones verbales o múltiples, coincidiendo con Pinto y Cañadas (2019), y la representación simbólica fue utilizada solamente cuando se les propuso desde el enunciado. Los resultados sugieren que las edades de los estudiantes influían en el uso de las representaciones, encontrando que los estudiantes de secundaria tenían una mayor tendencia a la representación simbólica, seguramente como consecuencia de su experiencia formativa y desarrollo cognitivo.

Finalmente, señalar que no hemos encontrado investigaciones en las que se trabaje de manera específica la generalización con personas ciegas. Sin embargo, destacamos el trabajo realizado por Viginheski et al. (2014b) pues si bien su enfoque no es la generalización, los autores exploran a partir del juego de la torre de Hanoi si 20 participantes ciegos pueden identificar regularidades y patrones en los movimientos y encontrar una forma de calcular la cantidad de movimientos para cualquier número de discos. Los estudiantes hicieron varias propuestas que fueron puestas en común por los autores con el grupo con sus respectivas expresiones algebraicas, para que los participantes encontraran el elemento en común y la fórmula general que pudiera relacionarlas. Se concluye entonces que es posible desarrollar con estudiantes ciegos (en este caso a través de la torre de Hanoi) conceptos matemáticos tales como generalización, búsqueda de patrones, potencias, pensamiento lógico, así como estrategias para la resolución de un problema, haciendo uso de conocimientos que han sido abordados previamente en la enseñanza regular.

\subsection{Talento y discapacidad visual}

rescatamos en este apartado aquellos estudios en los que se aborda la doble condición de NEE (superdotación y discapacidad visual) al estar relacionados de forma indirecta con este trabajo, 
así como estudios donde se aborda el desempeño de estudiantes ciegos en pruebas estandarizadas.

Uno de ellos es el realizado por Starr (2003), quien lleva a cabo un estudio con cinco estudiantes australianos superdotados y con discapacidad visual que tenían entre 3 y 16 años. Concluye, tal y como recoge en los antecedentes, que los estudiantes ciegos presentan altos resultados en fluidez, flexibilidad y originalidad verbal en las pruebas de escala verbal, como la Wechsler Intelligence Scale for Children - WISC. Así mismo, concluye un alto nivel de atención y concentración por parte de los participantes y la necesidad de la adaptación adecuada de los instrumentos para estos estudiantes. Igualmente, destacamos el estudio realizado por Rangni y Costa (2016) quienes hacen una revisión de publicaciones relativas a la doble condición de NEE (talento y discapacidad visual) en el periodo de 2003 a 2013. Estos autores reportan que tras realizar la búsqueda en libros especializados, documentos educativos y artículos de revistas académicas, encontraron solo ocho artículos de los que solo tres fueron considerados relevantes para el propósito investigado, pues la mayoría de ellos no estaban completamente disponibles. Esto viene a poner de manifiesto una vez más la escasez evidenciada en el tema. También el estudio realizado por Lopes y Gil (2016) quienes tienen como objetivo verificar si tres madres de niños con discapacidad visual identifican características y comportamientos propios de estudiantes superdotados en sus hijos.

En estos tres estudios, de manera general, se resalta la deficiencia de pautas en la literatura para identificar a estudiantes ciegos superdotados, sumado a al uso de métodos o instrumentos inadecuados que pueden no resaltar e incluso socavar las fortalezas y habilidades del estudiante; en general, hay una ausencia de oportunidades para la demostración de altas habilidades por parte de personas ciegas. Si lo particularizamos para el caso del talento matemático, que es tan solo una parte de la condición de superdotado, el panorama es aún más desalentador. Además, si partimos de que la identificación de un estudiante con talento en muchas ocasiones inicia de la postulación por parte de los padres o el profesor (Ramírez y Cañadas, 2018), un obstáculo que se encuentra para la identificación en el caso del estudiante ciego es la imposibilidad que se asume por parte de la familia y la comunidad educativa de la coexistencia de ambas excepcionalidades 
Por otro lado, destacamos el estudio de Viginheski et al. (2016) quienes analizaron el desempeño de dos estudiantes ciegos de $7^{\circ}$ y $8^{\circ}$ grado (13 y 17 años) en las olimpiadas brasileñas de matemáticas (OBMEP). Las autoras describen que el interés por esta investigación surge después de verificar un bajo desempeño de estos estudiantes en la prueba, por lo que su objetivo es investigar las posibles causas de este bajo rendimiento teniendo en cuenta las condiciones de enseñanza y aprendizaje de las matemáticas que se les proporciona en el aula. El primer aspecto que destacan es que tras analizar el desempeño de las clases donde se encontraban incluidos, se pudo verificar que el bajo desempeño fue generalizado. Los docentes señalaron que esta situación estaba asociada a la falta de conocimiento de contenidos básicos de la matemática, así como dificultades en el razonamiento y la abstracción. En el caso particular de los estudiantes ciegos, se resalta la falta de adaptación del material que se utiliza en clase para la instrucción, la cual, de acuerdo con los profesores participantes en el estudio y lo reportado en investigaciones anteriores, se lleva a cabo de forma oral, siendo en algunas ocasiones el único medio de acercamiento a las matemáticas por parte del estudiante ciego. Esta situación, según las autoras, no favorece la formación y mucho menos la generalización de conceptos, lo que contribuye de manera negativa en aspectos como la resolución de problemas. Estas autoras consideran que los estudiantes deben participar activamente en los procesos de enseñanza y aprendizaje, lo que exige pasar por todas las etapas (material, verbal y mental) garantizando las acciones y operaciones sobre los objetos matemáticos. Al respecto puntualizan:

Es evidente que una enseñanza de la matemática basada únicamente en planteamientos teóricos, sin experiencia concreta y significativa, en la que falta la participación directa del alumno por insuficiencia de recursos didácticos adecuados, tenderá a desarrollar, en cualquier alumno, una actitud desfavorable hacia la asimilación y comprensión de los contenidos desarrollados. (p. 7)

Los autores también exponen un ejemplo de adaptación de una de las figuras utilizadas en una de las preguntas de la prueba, la cual se hizo a través de relieve y notas complementarias de descripción (ver figuras 10 y 11 en Anexo 1). Al respecto, señalan que 
hay varios aspectos que pueden retrasar la comprensión del gráfico por parte del estudiante ciego y por tanto su tiempo de desempeño en la prueba: en primer lugar, la lectura táctil difiere significativamente de la lectura visual, tanto para los textos como para las figuras. Esto porque visualmente se perciben de un solo vistazo todas las letras que componen una palabra y los trazos que componen una figura, mientras que táctilmente la persona ciega debe ir descifrando letra por letra y cada parte de la figura para hacerse la construcción general de ésta. Y en segundo lugar, las descripciones que se proponen de la figura suelen nombrar conceptos matemáticos que deben ser conocidos previamente por el estudiante o dicha descripción no será significativa, además de exigir un mayor nivel de abstracción al tener que construir el gráfico mentalmente (Viginheski, 2004).

Esta teoría también es apoyada por Molina (1999) quien encontró en su investigación doctoral sobre la enseñanza de geometría a estudiantes ciegos que estos realizaron considerablemente más tarde las tareas que requerían habilidades espaciales-manipulativas, mientras que en las pruebas de carácter verbal no hubo diferencia en relación con las edades con respecto a los videntes. Además, señala que una de las dificultades que se presentan en el estudio de la geometría para el estudiante ciego es que el tacto, a diferencia del ojo que permite ver la figura en su conjunto y las relaciones entre sus partes de manera simultánea, es más lento en el reconocimiento de la figura al tener que recorrerla con los dedos e ir inspeccionando cada una de sus partes primero de manera aislada para luego tener una imagen completa de la figura y la impresión de sus magnitudes. Es decir que el estudiante ciego encuentra más dificultad en la comprensión de las condiciones básicas del problema geométrico que en la naturaleza misma de su resolución, lo que se puede extrapolar para toda situación matemática que involucre un gráfico o figura en su planteamiento. En este aspecto influye si la ceguera fue adquirida, puesto que la memoria visual contribuye mucho para la identificación de propiedades del objeto; mientras que si la ceguera es congénita, los conceptos deben explorarse en la etapa material por medio de objetos táctiles que exhiban estas propiedades, lo que no siempre se ofrece en el proceso educativo de estos estudiantes. 


\subsection{Adaptación de material: percepción háptica de las matemáticas y visualización}

En este apartado sintetizamos todos aquellos estudios en los que se trabaja la adaptación de materiales para el estudio matemático por parte de personas ciegas, las implicaciones, dificultades o ventajas que tiene, y cómo es aprehendido el contenido matemático cuando es adaptado para ser percibido desde el tacto.

La percepción háptica involucra sensaciones cutáneas (que son estáticas y son capturadas por receptores en nuestra piel) y sensaciones cinestésicas (que son dinámicas y se basan en el movimiento de músculos y tendones). Ambas sensaciones se combinan para sentir, percibir y pensar sobre los objetos, sus propiedades y el espacio en el que se inscriben (Lederman y Klatzky, 2009). Cuando se levanta un objeto para pesarlo (medir) y estimar la diferencia de peso con respecto a otro objeto (comparar), o cuando se señalan caminos existentes o imaginarios en un plano, se está utilizando la percepción háptica como una herramienta útil en el razonamiento matemático. Figueiras y Arcavi (2013) llevaron a cabo una investigación en la que examinaron las perspectivas hápticas de dos estudiantes ciegos y uno de baja visión que aprenden sobre sólidos de revolución con la instrucción de un profesor también ciego. Concluyen en la misma línea de otros estudios que, aunque el tacto y la visión proporcionan información redundante, la visualización implica mucho más que el sentido de la visión, por lo que una visión deficiente o inexistente no necesariamente impide visualizar. De hecho, traen a colación la experiencia que tuvo una profesora con los ojos vendados al tocar una parábola, quien encontró desde el tacto cuestiones que con la vista no habían sido percibidas o se habían pasado por alto. Al respecto, los autores postulan que si la percepción háptica mejora la visualización de aspectos de un gráfico de una función, también podría desempeñar un papel importante en el apoyo y mejora de ciertos aspectos del razonamiento en muchas otras áreas de las matemáticas, especialmente en geometría. De hecho, van más allá y plantean que saber cómo los estudiantes ciegos conducen sus experiencias hápticas se convierte en una fuente razonable de ideas para ampliar las perspectivas sobre la visualización. Además, encontraron que, contrario a lo que podría imaginarse, en la clase se observó que dichas experiencias hápticas suelen ser complementadas por la alusión a objetos y situaciones 
cotidianas, que muchas veces incluyen imágenes puramente visuales. Así, destacan que los recursos lingüísticos, como por ejemplo las metáforas visuales, parecen actuar como un componente esencial en la representación de ideas matemáticas. "El poder de las metáforas para el aprendizaje de las matemáticas reside en su uso para dar sentido a nuevas ideas u objetos (matemáticos) en términos de los ya existentes (a menudo no matemáticos)" (Figueiras y Arcavi, 2013, p. 126), pero en el caso de la persona ciega las metáforas son usadas para dar sentido a ideas u objetos en su contexto en términos de ideas matemáticas ya existentes.

En la misma línea, Stylianidou y Nardi (2019) llevan a cabo una investigación en la que pretenden mostrar el beneficio de una construcción táctil de los conceptos matemáticos tanto para ciegos como videntes, y señalan que, si bien muchas veces las adaptaciones táctiles de las formas visuales son efectivas, en ocasiones estas presentan limitaciones. Un ejemplo de tipo técnico es cuando el lector de pantalla que usan los estudiantes ciegos interpreta notaciones matemáticas como imágenes y no hace una correcta lectura de ellas, así como errores o elementos faltantes en las impresiones de textos en braille que no son detectadas y corregidas antes de entregar el material al estudiante. También están las de tipo afectivo y social, que se presentan en la adaptación de una tarea visual con patrones lineales representados con puntos de diferentes colores. La sustitución de los colores por diferentes texturas puede conducir a una sobrecarga de procesamiento para los estudiantes ciegos y también a dificultades en la comunicación con sus pares videntes o incluso profesores sobre la tarea matemática. No obstante, tal y como recogen Neves y Maia (2018), este contraste de texturas es necesario no solo para distinguir diferentes patrones lineales, sino para resaltar algunas características del objeto que está siendo adaptado; también puntualizan sobre la adaptación que el relieve debe ser fácilmente percibido por el tacto, no debe causar rechazo al manejo y ser propicio para la exploración y manipulación táctil. Por último, tener en cuenta que "el propósito de una ilustración táctil es comunicar una idea o información, no replicar una representación visual en forma táctil” (Rosenblum y Herzberg, 2015, p. 175).

Por tanto, es innegable que en el caso del estudiante ciego la primera vía de acceso a la información del objeto de estudio matemático se da a través del tacto con la ayuda de material didáctico manipulable. Esto permite, por un lado, nuevas formas de aprendizaje, con la 
apropiación del concepto enseñado y la posibilidad de acción sobre el objeto de conocimiento; y por otro, la preparación del estudiante para resolver situaciones-problema que le sean propuestas (Shimazaki et al., 2015). Por tanto, la falta de adaptación del material que se utiliza en el aula conlleva para el estudiante ciego un retraso en la construcción que hace de los conceptos matemáticos y del espacio (Fernández, 1995). Dicha adaptación puede ser también de tipo verbal (Viginheski et al., 2014a) como se muestra en la figura 12 del Anexo 2.

De acuerdo con los autores, este tipo de adaptación tornó la pregunta bastante compleja y abstracta para la persona ciega, pues requiere, además de los conocimientos en geometría analítica, la necesidad de construir el gráfico mentalmente solo con la ayuda de una descripción hecha a partir de un gráfico visual, lo que conlleva una desventaja para la persona ciega que se está examinando con respecto a sus pares videntes. Por tanto, recomiendan evitar adaptaciones complejas y señalan que en este caso el gráfico puede ser presentado en relieve como se muestra en la figura 13 del Anexo 2.

Esta adaptación permite al alumno ciego acceder a la información de la misma forma que los alumnos videntes, y por tanto la adaptación que se realice va a depender de la complejidad de lo que se quiere adaptar. Además, señalan que antes de realizar la adaptación se debe pensar si se trata de una figura lineal, en la que los trazos son importantes, o si la figura está compuesta por formas cerradas. Esta variación implicará una adecuación de recursos que enfaticen relaciones lineales o relaciones entre áreas y formas. Agregan que dicha adaptación debe ser realizada por una persona que tenga conocimiento en el contenido que está siendo adaptado para poder transmitir todos los detalles necesarios para que el ciego pueda comprenderla, así como la necesidad de en ocasiones acompañar dicha adaptación de una guía por parte del profesor. Al respecto, citando a Reily (2004) puntualizan:

Hay formas de hacer que la imagen sea accesible para los ciegos, que tiene, como todos nosotros, el derecho a ser público (y también productor, ¿por qué no?) de la cultura de la imagen. Es necesario realizar una conversión semiótica, de tal manera que el signo visual sea aprehendido por vía táctil-verbal. La palabra del otro describe y significa, y la persona ciega se apropia del sentido, trayendo sus experiencias personales a la situación. (p. 913) 
Finalmente, para el caso de objetos tridimensionales, señalan que la representación de tales objetos no proporciona táctilmente la misma percepción que visualmente. Es aconsejable utilizar estas representaciones con reserva, y agregar, a la información táctil, información verbal. Asimismo, es importante utilizar el tamaño adecuado para el reconocimiento táctil y la utilización de objetos con las formas, sean planas o tridimensionales. De igual manera, Rosenblum y Herzberg (2015) llevaron a cabo una investigación en la que pretendían recopilar información directamente de los jóvenes lectores de braille sobre sus experiencias con gráficos táctiles y el material braille que reciben en clase, y concluyeron que muchas veces los estudiantes ciegos tienen dificultades para interpretar los gráficos debido a que no se les prepara para ello. Los participantes de la investigación reportaron que normalmente no reciben el gráfico adaptado a la vez que sus compañeros videntes, y esto los pone en desventaja con respecto al conocimiento que adquieren del objeto matemático y a su vez de la capacidad para leer e interpretar gráficos táctiles. Además, manifestaron que para una adecuada comprensión el gráfico debe estar correctamente etiquetado en braille y con suficiente espacio entre las diferentes texturas para facilitar la legibilidad.

\section{METODOLOGÍA}

Este trabajo se realiza bajo un enfoque cualitativo, el cual "no pretende generalizar de manera intrínseca los resultados a poblaciones más amplias, ni necesariamente obtener muestras representativas, sino que se fundamenta más en un proceso inductivo" (Hernández et al., 2010, p. 16). Dado que pretendemos descubrir y describir los fenómenos buscando información en los datos, la naturaleza de la investigación es descriptiva. Adicionalmente, tal y como expusimos en el capítulo de antecedentes, los estudios sobre aspectos relacionados con la identificación del talento matemático en personas con discapacidad visual y la manifestación de sus características son escasos, por lo que este trabajo es de carácter exploratorio. El estudio de la influencia de la discapacidad visual en la manifestación de características tales como la generalización y habilidades de sentido espacial, se ha realizado con base en las pruebas de acceso 
al programa ESTALMAT, el cual tiene como objetivo detectar y estimular el talento precoz en matemáticas.

\subsection{Sujetos}

En esta investigación participaron dos sujetos: la persona investigada (autora) y quien proporcionó las descripciones de las tareas (cotutor de la investigación). Esta muestra es intencionada ya que, como expusimos en la justificación y antecedentes, el estudio con personas ciegas es complejo al no poder acceder fácilmente a un grupo con una cantidad considerable de participantes de esta población. Por tanto, realizamos el estudio con el sujeto al que tenemos acceso, conscientes de que no proporciona datos susceptibles de generalizar, sino tan solo información que nos permite sumar para un proceso inductivo.

La autora y sujeto participante en la investigación es una persona ciega con diagnóstico de retinoblastoma bilateral, lo que da como resultado una ceguera total a partir de los dos años y medio. Su formación universitaria es en licenciatura en matemáticas y física. Esta carrera es la que se sigue en Colombia para formarse como profesor, y por tanto, se compone de asignaturas del conocimiento específico (disciplinar), pedagógico y didáctico. La línea disciplinar comprende diferentes asignaturas propias de la física y las matemáticas como cálculos, álgebra lineal, geometría euclidiana y vectorial, entre otros. En relación con la participación en esta investigación, es importante mencionar que no tiene un diagnóstico de talento matemático, pero sí ha participado en olimpiadas de matemáticas organizadas en la ciudad de Medellín mientras cursaba noveno grado de la educación secundaria colombiana (14-15 años), lo que le ha permitido observar las falencias que hay al respecto desde el punto de vista de estudiante.

Por otro lado, Rafael Ramírez, codirector de este trabajo, es coordinador del proyecto ESTALMAT en Andalucía Oriental por lo que ha participado en el diseño y evaluación de la prueba de selección que se analiza. Una de sus líneas de investigación es el sentido espacial y el pensamiento funcional en estudiantes con talento matemático, que son las dos temáticas de los problemas analizados. María C. Cañadas ha colaborado en el diseño de una de las tareas 
que empleamos en esta investigación y su línea de trabajo es el pensamiento algebraico, en el que se enmarca el pensamiento funcional.

\subsection{Características del talento matemático}

En este apartado exponemos las características enunciadas por Greenes (1981), Miller (1990) y Freiman (2006). En la tabla 1, construida por Ramírez (2012) se expone una interrelación entre dichas características y subrayamos aquellas relacionadas con la generalización, sobre las que pondremos el foco en nuestra investigación.

Tabla 1. Características del talento matemático.

\begin{tabular}{lll}
\hline \multicolumn{1}{c}{ Greenes (1981) } & \multicolumn{1}{c}{ Miller (1990) } & \multicolumn{1}{c}{ Freiman (2006) } \\
\hline $\begin{array}{l}\text { Formulación espontánea de } \\
\text { problemas }\end{array}$ & & - Pregunta espontáneamente cues- \\
& & tiones que van más allá de \\
& & $\begin{array}{l}\text { las tareas matemáticas que se le } \\
\text { plantean }\end{array}$ \\
Flexibilidad en la manipulación & Gran capacidad para pensar y & - Cambia fácilmente de una es- \\
de datos & trabajar con problemas mate- & trategia a otra, de una estructura \\
& máticos de una forma flexible & a otra \\
& y creativa & \\
Habilidad para la organización & Rapidez para aprender, entender & - Localiza la clave de \\
de datos & y aplicar las ideas matemáticas & los problemas \\
& & - Busca patrones y relacio- \\
& & nes, construye nexos, lazos \\
ideas (pensamiento divergente) & & y estructuras matemática \\
Originalidad de interpretación & & - Mantiene bajo control \\
& & los problemas y su reso- \\
& & lución \\
& & - Presta atención a los detalles \\
& & - Produce ideas origina- \\
& & les, valiosas y extensas. \\
& & - Desarrolla estrategias eficientes. \\
& & - Piensa de modo crítico \\
& &
\end{tabular}




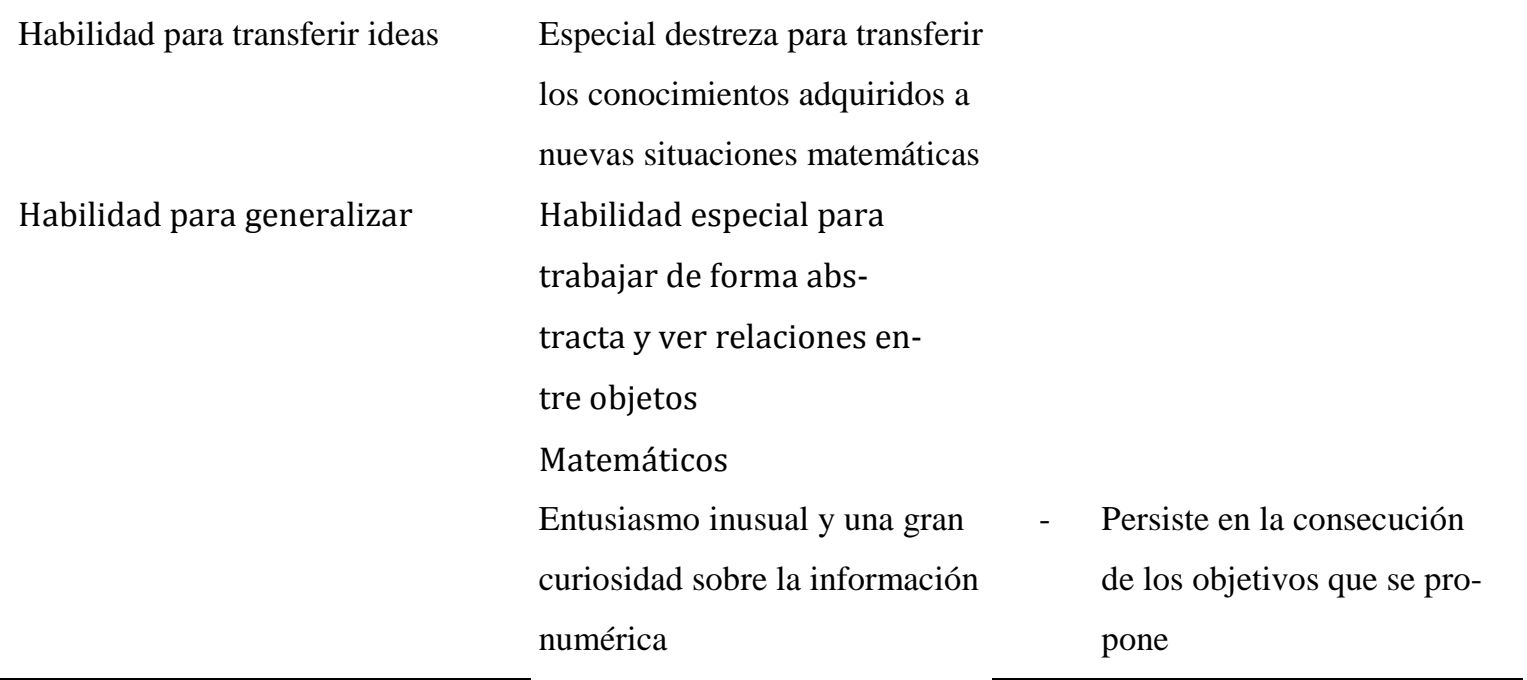

Nota. Fuente: Ramírez (2012)

\subsection{Instrumento}

La prueba que hemos analizado en este trabajo corresponde a la convocatoria de junio de 2017. Esta constaba de cinco tareas, de las cuales hemos seleccionado la primera y la última para su análisis. La primera requiere la activación de algunas componentes del sentido espacial y la generalización, siendo esta última el enfoque y fin último de la tarea; mientras que la última se centra específicamente en la activación de las componentes del sentido espacial y habilidades de visualización, por lo que permite un análisis más profundo de estas. Adicionalmente, la elección de estas tareas se ha basado en el carácter visual que engloban, por lo que su análisis con respecto a la resolución por parte de una persona ciega resulta de gran interés. Finalmente, estas tareas también se han analizado en varias investigaciones (Aznarte, 2018; Ureña et al., en revisión) resaltando el potencial para analizar aspectos relativos a las componentes del sentido espacial y la generalización. Estas investigaciones permiten un contraste que enriquece los resultados de nuestro trabajo. El análisis completo de las componentes del sentido espacial, generalización y características del talento esperables en las tareas aparece en Anexo 3, mientras que en el trabajo se enfatizará lo relativo a la adaptación posterior. 
A continuación, exponemos las tareas en su estado original. Igualmente, exponemos las versiones modificadas que fueron presentadas a la persona ciega para que pudiera acceder al contenido, previo al estudio sobre la adaptación de las mismas.

\section{Tarea 1. Sembrando Semillas}

a) Versión original

Un agricultor se dispone a sembrar semillas de patatas en su terreno.

El primer día, el agricultor siembra tres semillas en línea recta separadas 1 metro entre cada dos consecutivas (como se indica en la figura de la derecha).

El segundo día, vuelve a sembrar otras tres semillas en una línea paralela a la anterior a distancia 1 metro y también a distancia 1 metro entre cada nueva semilla.

1.- Tras la siembra del tercer día, el campo queda de la siguiente forma:

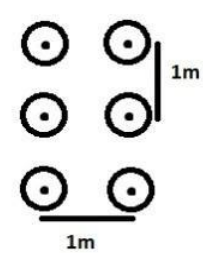
$\odot \odot \odot$
a) ¿Cuántos cuadrados pueden formarse de modo que las semillas

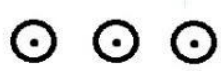
$\odot \odot \odot$ sean sus vértices en el tercer día? Dibújalos en el campo anterior y cal- cula el área de cada uno de ellos.

b) Llamamos orden de una semilla al número de cuadrados que tienen alguno de sus vértices en dicha semilla. ¿Cuál es el orden de cada una de las semillas?

¿Cuánto vale la suma de los órdenes de todas las semillas?

2.-El agricultor sigue cultivando tres semillas cada día con la misma distribución anterior. Tras la siembra del cuarto día,

a) ¿Cuántos cuadrados pueden formarse de modo que las semillas sean sus vértices? Dibújalos en el campo del cuarto día y calcula el área de cada uno de ellos.

b) ¿Cuál es el orden de cada una de las semillas? ¿Cuánto vale la suma de los órdenes de todas las semillas?

3.- Si han pasado 100 días, responde justificando tu respuesta, a las siguientes preguntas:

a) ¿Cuántos cuadrados pueden formarse de modo que las semillas sean sus vértices? ¿Qué área tienen 
cada uno de esos cuadrados?

b) ¿Cuánto vale la suma de los órdenes de todas las semillas?

4.- Si han pasado " $n$ " días (n representa cualquier valor de los días de siembra), responde justificando tu respuesta, a las siguientes preguntas:

a) ¿Cuántos cuadrados pueden formarse de modo que las semillas sean sus vértices? ¿Qué área tienen cada uno de esos cuadrados?

b) ¿Cuánto vale la suma de los órdenes de todas las semillas?

\section{Figura 1. Tarea Sembrando Semillas (versión original)}

La siguiente fue la versión que resolvió la participante en la investigación, a la que en adelante llamaremos tarea 1 .

b) Versión adaptada

Dadas las circunstancias especiales del año en curso, el acceso a la tarea por parte de la persona ciega fue por vía digital. Debido a que el lector de pantalla no interpreta gráficos ni imágenes a voz, el acceso a la imagen que acompaña el texto se vio limitado y por tanto la modificación en este caso consistió en resolverlo sin este apoyo visual. Por lo demás, ni el planteamiento ni las preguntas se vieron modificadas. Como la tarea fue presentada sin el gráfico, los esquemas correspondientes (ver figuras 3, 5 y 6) debieron ser realizados por la persona ciega con el uso de material tiflotécnico (goma para dibujo, pauta, punzón y bolígrafo para las diferentes texturas). Estos esquemas fueron realizados a partir de la interpretación de lo expuesto en el enunciado.

\section{Tarea 2. Pintando Cubos y Cubitos}

a) Versión original 
Hemos necesitado exactamente 9 botes de pintura para pintar exteriormente (por todas sus caras, también las que no se ven, como la lateral izquierda, la trasera y la inferior) el cubo de la izquierda que,

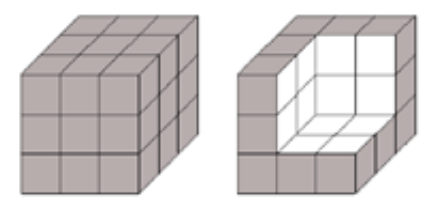
como se ve, está construido adosando cubitos todos iguales.

Después hemos quitado unos cuantos cubitos para dejar la figura como se ve a la derecha.

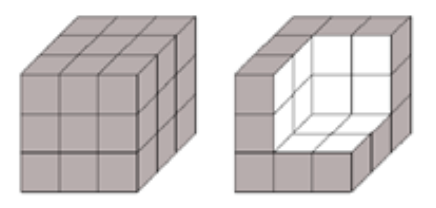

1. ¿Cuántos botes de pintura necesitaremos para pintar completamente la parte de la figura que no lo está? Ahora ya tenemos esta figura pintada exteriormente (recordad que también por la izquierda, por detrás y por debajo). Vamos a desmontarla y adosando algunos cubitos en la posición que nos vaya mejor, que-

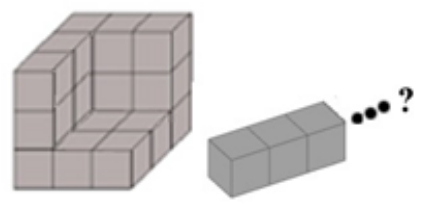
remos construir una fila de cubitos, en la que queremos pintar todas las caras que no lo estén.

Tenemos un solo bote de pintura como los del apartado a).

2. ¿Cuál es el máximo número de cubitos que podremos poner en la fila para que la podamos pintar completamente? Explica cómo los tienes que colocar.

Tenemos otro cubo como el inicial, completo y pintado exteriormente por todas sus caras, lo desmontamos y ahora queremos adosar adecuadamente algunos cubitos (algunos de los cuales tienen caras pintadas)
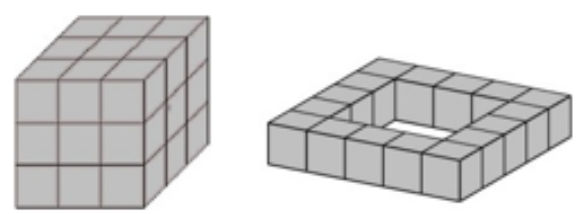
para construir un nuevo objeto: un "cuadrado de cubitos" y pintarlo, como se ve en la figura de la derecha.
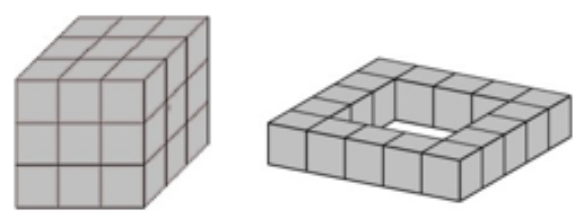
Queremos pintar todas las caras exteriores del nuevo objeto, pero lo podemos montar de manera que aprovechemos piezas con algunas caras pintadas, tantas como sea posible (que ya no volveremos a pintar, naturalmente)

3. Razona cuál es el menor número de caras que deberemos pintar.

Con las piezas que nos han sobrado queremos añadir una cruz al cuadrado y que quede pintada en todo su exterior, como muestra la figura de la derecha

También la montaremos intentando aprovechar, de los cubitos que nos han quedado sin utilizar, aquellos que tengan caras ya pintadas y que podemos añadir ahora a la construcción.

4. ¿Cuál es el menor número de caras que deberemos pintar en la cruz que añadimos?

Figura 2. Tarea 2 Pintando cubos y cubitos (versión original)

A continuación, exponemos la versión que fue resuelta por la persona ciega, cuya modificación consistió en una descripción detallada de las imágenes que incluye el enunciado. Por lo demás, ni el planteamiento ni las preguntas se vieron modificadas. En adelante la llamaremos tarea 2.

b) Versión modificada

En este caso la adaptación consistió en describir cada una de las imágenes, y la tarea para la persona ciega fue presentada por escrito de la siguiente manera.

Hemos necesitado exactamente 9 botes de pintura para pintar exteriormente (por todas sus caras, también las que no se ven, como la lateral izquierda, la trasera y la inferior) el cubo de la izquierda que, como se ve, está construido adosando cubitos todos iguales.

Explicación de las imágenes:

Aparecen dos imágenes.

Imagen 1: En la primera se ve en perspectiva un cubo. Está dividido en 27 cubitos (3x3x3) de manera similar a un cubo de Rubik.

Se ven tres de sus caras (adelante, derecha y arriba) y todo lo que se ve está pintado de gris. Imagen 2: En la segunda imagen se han suprimido del cubo anterior 8 cubitos. Se ha eliminado el cubito de la esquina superior derecha (el vértice donde coinciden la cara anterior, derecha y 
arriba) y los siete cubitos que contactan con él). Las caras de los cubitos que quedan están pintadas de gris las que correspondían al exterior del cubo y ahora están de blanco las que se correspondían a caras interiores respecto a primera figura. Se ven por tanto pintadas de blanco 12 caras de los cubitos que forman la figura 2.

Continúa el problema:

Ahora ya tenemos esta figura pintada exteriormente (recordad que también por la izquierda, por detrás y por debajo). Vamos a desmontarla y adosando algunos cubitos en la posición que nos vaya mejor, queremos construir una fila de cubitos, en la que queremos pintar todas las caras que no lo estén.

Tenemos un solo bote de pintura como los del apartado a).

2. ¿Cuál es el máximo número de cubitos que podremos poner en la fila para que la podamos pintar completamente? Explica cómo los tienes que colocar.

Ahora aparecen dos imágenes:

Imagen 3: La misma que la figura 2 con todas las caras pintadas de gris.

Imagen 4: Tres cubitos unidos consecutivamente (cada cubo toca al siguiente en una cara lateral, formando una tira de tres cubitos). Se ve en perspectiva la cara de arriba, adelante e izquierda del primer cubito, la cara de arriba y adelante del segundo y la cara de arriba y adelante del tercero.

Continúa el problema

Tenemos otro cubo como el inicial, completo y pintado exteriormente por todas sus caras, lo desmontamos y ahora queremos adosar adecuadamente algunos cubitos (algunos de los cuales tienen caras pintadas) para construir un nuevo objeto: un "cuadrado de cubitos" y pintarlo, como se ve en la figura de la derecha. Queremos pintar todas las caras exteriores del nuevo objeto, pero lo podemos montar de manera que aprovechemos piezas con algunas caras pintadas, tantas como sea posible (que ya no volveremos a pintar, naturalmente).

3. Razona cuál es el menor número de caras que deberemos pintar.

Ahora aparecen dos imágenes:

Imagen 5: La misma que la imagen 1 
Imagen 6: Se ven en perspectiva 16 cubitos formando un cuadrado de $5 \times 5$ cubitos cada lado. Se ven todas las caras superiores y tiene una perspectiva que permite ver las laterales de algunos cubos. Todo lo que se ve está gris.

Continúa el problema

Con las piezas que nos han sobrado queremos añadir una cruz al cuadrado y que quede pintada en todo su exterior, como muestra la figura de la derecha.

También la montaremos intentando aprovechar, de los cubitos que nos han quedado sin utilizar, aquellos que tengan caras ya pintadas y que podemos añadir ahora a la construcción.

4. ¿Cuál es el menor número de caras que deberemos pintar en la cruz que añadimos?

Imagen 7: ES la misma que la imagen 6, pero tiene añadido cuatro cubitos formando una cruz en el interior del cuadrado 5x5, uniendo los cubitos centrales de cada lado del cuadrado $5 \times 5$. La perspectiva es casi la planta, viéndose todos las caras de arriba de los cubitos pintadas de gris y algunas laterales.

\subsection{Categorías de análisis}

En este trabajo utilizaremos como unidad de análisis la respuesta proporcionada por la participante a cada uno de los apartados de las tareas. Las categorías de análisis las establecemos basándonos en los objetivos de la investigación y los planteamientos del marco teórico. En el análisis del sentido espacial, nos focalizaremos en las componentes relativas al conocimiento geométrico (elementos, relaciones y ubicación) y a las habilidades de visualización. No consideraremos otros elementos de la visualización, como las imágenes, representaciones y procesos por el tipo de tarea que se planteó. Para ello tomamos como referencia las componentes establecidas por Flores et al. (2015) y las habilidades recopiladas por del Grande (1990). Estas categorías a su vez fueron utilizadas en el estudio hecho por Aznarte (2018), en las que nos basamos reinterpretándolas desde la perspectiva de personas ciegas. Por otro lado, para el análisis de la generalización nos basaremos en la definición proporcionada por Kaput (1999) y las categorías establecidas por Ureña et al. (en revisión). Por tanto, nuestras categorías son las siguientes: 


\section{Sentido espacial}

A continuación, exponemos las componentes con los criterios que tuvimos en cuenta para registrar su activación:

a) Elementos geométricos. Menciona conceptos como aristas, diagonales, altura, hipotenusa, vértices, superficie, entre otros; clasifica y discrimina figuras como cuadrados, triángulos y cubos.

b) Relaciones geométricas. Hace Referencia al tamaño de algún elemento (grande, pequeño...).), así como referencias a relaciones tales como perpendicularidad, paralelismo, entre otras.

c) Ubicación y movimientos. Hace alusión a posiciones en el plano o en el espacio y realización de movimientos reconociendo en ellos regularidades o elementos invariantes. Por ejemplo, giros y composiciones de figuras (referencia a las distintas caras de los cubos en relación con el plano al girarlos, cara lateral, la de arriba, en la superficie...); su posición con respecto al otro (Esquinas, interior, exterior, arriba, mitad...), y continuidad (uno al lado, detrás o delante del otro, consecutivo). En este caso, entendemos que dichos movimientos pueden ser mentales, puesto que no se dispone de material físico.

d) Habilidades de visualización:

- Coordinación visomotora. Coordina la visión con el movimiento del cuerpo. Dada la naturaleza de las tareas presentadas, esta categoría no se analiza en este estudio.

- Percepción figura-contexto. Identifica los cuadrados dentro de la distribución de semillas dada u otras figuras en el caso de la tarea con cubos, manifestada a través de las descripciones, los esquemas o dibujos que realiza la persona ciega.

- Conservación de la percepción. Alude a propiedades que se mantienen al mover o al girar las figuras geométricas, como por ejemplo el caso del cuadrado apoyado sobre su vértice o el reconocimiento de invariantes en el caso de los cubos cuando se manipulan mentalmente. 
- Percepción de la posición en el espacio. Hace referencia a la posición de los cuadrados, las semillas o los cubos con respecto a sí misma. Por ejemplo delante, atrás, izquierda, derecha.

- Percepción de relaciones espaciales. Compara medidas (más grande, más pequeño) y hace referencia a relaciones como perpendicular a o paralelo a, bien entre figuras o bien con respecto al propio cuerpo.

- Discriminación visual. Hace alusión a un conjunto de cuadrados, cubos o semillas que ha discriminado señalando sus semejanzas o diferencias, como por ejemplo la alusión a los cuadrados de área $\mathrm{x}$, cuadrados grandes o pequeños, entre otros.

- Memoria visual. Demuestra habilidad para recodar objetos a los que ha tenido acceso pero que no tiene justamente delante, para relacionarlos con otros objetos a los que tiene acceso de manera verbal pudiendo hacer una construcción mental o táctil de los mismos. En este caso por imagen visual entendemos toda imagen que la persona se pueda crear, independientemente del sentido (visión, tacto, audio) que le dé acceso al objeto del cual se está creando dicha imagen.

\section{Generalización}

Esta categoría solo se podrá analizar en la tarea 1. Nos enfocaremos en analizar el proceso que se sigue para llegar a la generalización, identificando la regularidad en unos casos considerados y extendiendo el razonamiento para encontrar los patrones, estructuras o relaciones que se presentan. En este sentido y de acuerdo con Ureña et al. (en revisión), entendemos que la representación de la generalización de una relación funcional se da cuando se expresa una regularidad subyacente a la tarea. En relación a las características del talento mencionadas, buscaremos alusiones a patrones, organización de datos, entre otros, todos ellos características propias de la generalización en estrecha relación con el razonamiento inductivo.

Para la representación de la generalización analizamos las siguientes categorías:

Verbal: Cuando las cantidades indeterminadas, sus relaciones y la regularidad detectada es expresada por medio de lenguaje natural. 
Simbólica: Cuando las cantidades indeterminadas, sus relaciones y la regularidad detectada es expresada por medio de simbolismo algebraico.

\section{Resultados}

En este capítulo realizaremos un análisis de los datos obtenidos con el fin de dar respuesta a cada uno de los objetivos de la investigación. Para ello diferenciaremos entre las características que son demandadas en las tareas y las que son puestas de manifiesto por la participante con discapacidad visual, finalizando con una propuesta de posible adaptación para las tareas en caso de que deban ser resueltas por personas ciegas.

\subsection{Análisis del sentido espacial y generalización por la participante con discapacidad visual}

En este apartado realizamos un análisis de las características del sentido espacial y de la generalización que fueron puestas en juego por la participante al resolver las dos tareas en relación con las categorías que se definieron en el anterior capítulo. Destacamos que la resolución de las tareas se realizó previamente a la revisión teórica, sin haber consultado ninguna referencia. Esto con el fin de que fuera lo menos contaminada posible. Los fragmentos que se citan aquí son tomados literalmente de la resolución y los analizamos a la luz de toda la teoría consultada. Con el fin de facilitar la lectura, a la tarea 1 la llamaremos t1 y a la tarea 2 t2.

\section{Sentido espacial}

a) Elementos geométricos

Esta componente del sentido espacial la vemos manifestada en la resolución a ambas tareas. Como se observa en el siguiente fragmento de la resolución de t1 (primer apartado), hay una utilización de diferentes conceptos geométricos en los que se evidencia su identificación y clasificación, al igual que la gráfica realizada manifiesta la comprensión de los conceptos y situación geométrica descrita en el enunciado: 


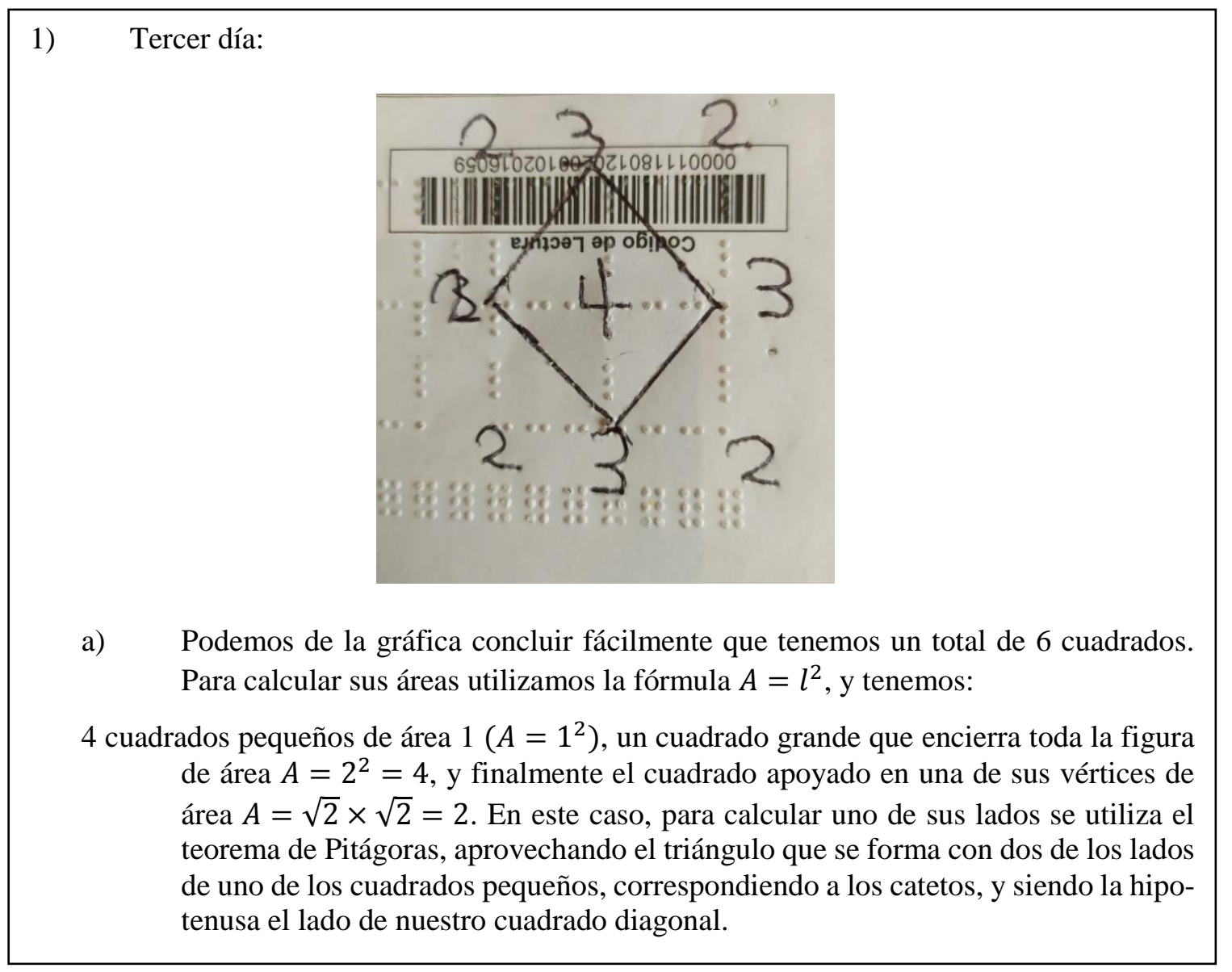

\section{Figura 3 Respuesta al apartado 1 de 11}

Igualmente, en el caso de t2 la vemos manifestada en la utilización de términos como "cubos", "caras", "cuadrado", entre otros.

\section{b) Relaciones geométricas}

Al igual que la anterior, esta componente se manifiesta en la resolución a ambas tareas. En el fragmento expuesto anteriormente se hace referencia a tamaño de los cuadrados, distinguiendo entre grandes y pequeños, al igual que en la gráfica realizada se manifiesta la comprensión de relaciones tales como paralelo a, que fueron utilizados en el enunciado. La correcta interpretación de estas relaciones es especialmente relevante en este caso, puesto que 
una incorrecta interpretación de lo descrito en el enunciado llevaría a una representación diferente de la planteada, y por tanto una resolución inadecuada de la tarea.

En la resolución de $\mathrm{t} 2$ se hace mención a relaciones de perpendicularidad y paralelismo, como se evidencia en el siguiente fragmento:

En el cubo inicial tenemos un total de 27 cubos. Al suprimir la parte que se aprecia en la segunda imagen, quedo con un total de 19 cubos, de los cuales 3 van a tener cuatro caras pintadas, 10 tres caras pintadas, de los cuales 6 coinciden en la forma, es decir, que tienen pintadas dos caras paralelas (las caras de adelante y atrás) y una perpendicular a ellas (la cara de arriba); mientras que 4 de ellos (los de las esquinas) las caras pintadas son perpendiculares entre sí (la cara de arriba, delante e izquierda); y finalmente 6 dos caras pintadas, donde 3 de ellos tienen caras paralelas pintadas (arriba y abajo) y los otros caras perpendiculares (arriba y delante).

Figura 4. Respuesta al apartado 1 del t2

Es importante destacar que la resolución a esta tarea fue realizada en su totalidad a partir de representaciones mentales manifestadas únicamente a través de descripciones verbales, de ahí el detalle en las relaciones y la descripción de las caras pintadas y las caras blancas.

c) Ubicación y movimientos

A diferencia de lo expuesto por Aznarte (2018) encontramos que se hizo mayor referencia a esta componente en la resolución de $\mathrm{t} 2$ que en $\mathrm{t} 1$, donde Se enfatizan los elementos de localización de los cuadrados. Esto lo vemos reflejado en fragmentos como “(...) un cuadrado grande que encierra toda la figura (...)", “(...) el orden de la semilla que queda en la mitad de la figura (...)", "(...) el orden de las semillas que quedan al interior de la figura (...)"; mientras que en t2 la encontramos incluso protagonista Relativa a la ubicación respecto al cubo inicial. Postulamos que esto puede deberse al tipo de resolución a la que acude la participante ciega, pues al tener que describir las figuras y cómo se conforman, necesariamente hace todo el tiempo alusión a giros que realiza de los cubos para ubicar convenientemente la posición de las caras. Por ejemplo, en el fragmento expuesto en el apartado anterior se puede apreciar aunque no lo menciona explícitamente- que cuando hace referencia a los cubitos ubicados en las esquinas, realiza un giro a dos de ellos para que su posición con respecto a sí misma y el 
plano sea la misma para los cuatro y así facilitar la descripción de la situación y las posteriores figuras que forma.

Asimismo, encontramos referencia a esta componente en los los apartados 1,2 y 3 de t2 (ver anexo 4).

d) Habilidades de visualización

- Percepción Figura-contexto. Encontramos referencia a esta habilidad en ambas tareas, pero destacamos su papel en t1, pues resulta fundamental para su resolución. Esto queda evidenciado en la figura 3, así como en las siguientes dos figuras en las que realiza un esquema para mostrar los cuadrados que se forman y posteriormente identificarlos de manera verbal.

a) De la gráfica podemos concluir que hay un total de 10 cuadrados, de los cuales 6 tienen área igual a 1, 2 cuadrados un área igual a 4, y finalmente 2 cuadrados diagonales de área 2.

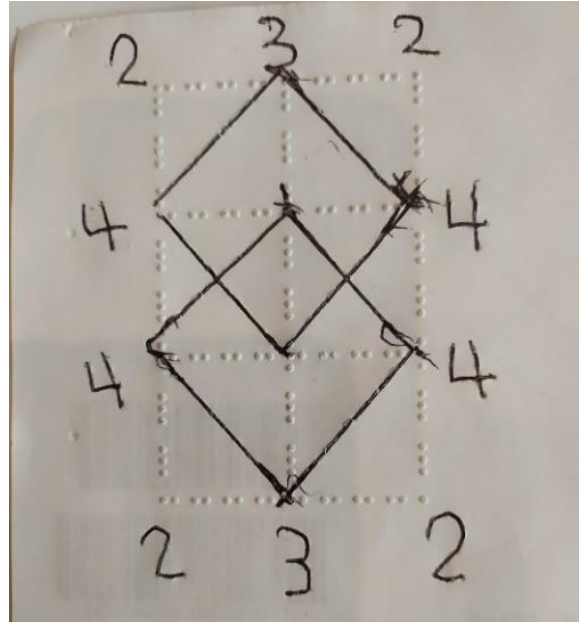

Figura 5. Gráfica del cuarto día 


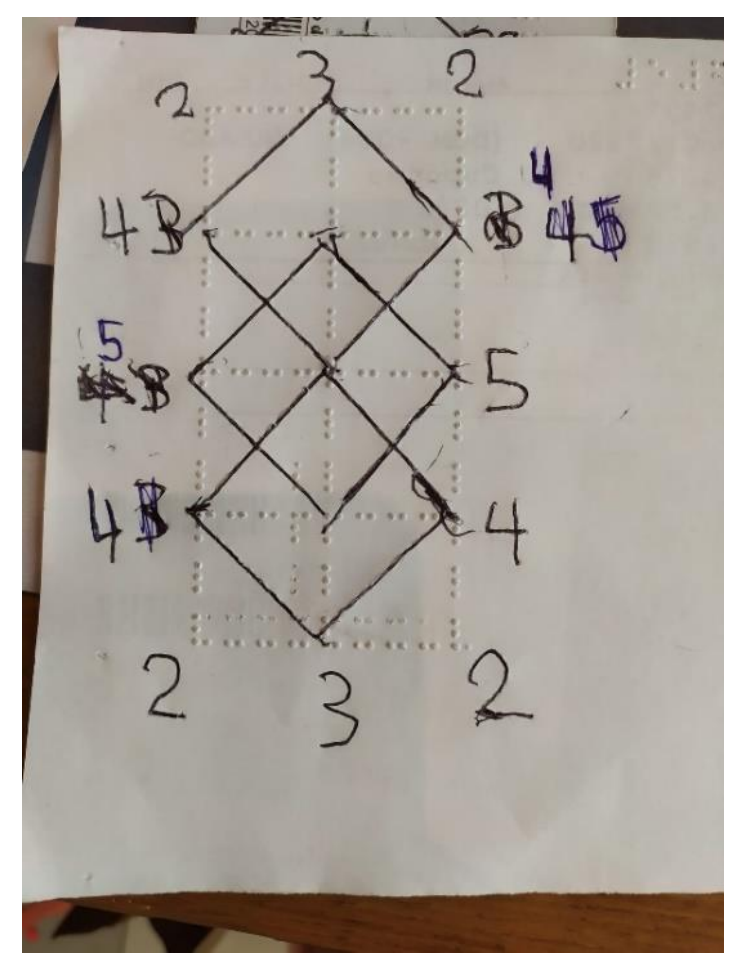

Figura 6. Gráfica del quinto día

En el caso de t2 la vemos manifestada en el aislamiento del cuadrado y la cruz para contabilizar el número de caras que deben ser pintadas una vez construidas ambas figuras, como se puede evidenciar en los fragmentos 2 y 3 de t2 (ver ANEXO 4).

- Conservación de la percepción. Al igual que la anterior habilidad, consideramos que ésta tiene un mayor protagonismo en el caso de t1, puesto que es la que permite reconocer el cuadrado apoyado sobre una de sus vértices Conservando las propiedades de igualdad de lados y ángulos de 90 grados. Sin el reconocimiento de éste, no sería posible llegar a la fórmula de generalización adecuada para el número de cuadrados ni la suma del orden de las semillas. Esta habilidad queda manifestada tanto en los esquemas ya expuestos como en el conteo que hace de los cuadrados y la alusión a éste como "cuadrado diagonal" en diferentes momentos de la resolución.

De igual manera, en $\mathrm{t} 2$ se evidencia en los diferentes cambios de posición que hace de los cubos reconociendo que estos mantienen su forma $\mathrm{Y}$ analizando las caras opuestas. 
- Percepción de la posición en el espacio. Esta habilidad la vemos manifestada en la resolución a ambas tareas, pero de manera particular en t2. En esta constantemente se está haciendo referencia a posiciones con respecto a sí misma (adelante, izquierda, derecha), añadiendo incluso una nota aclaratoria para especificar este punto.

- Percepción de relaciones espaciales. Esta habilidad se manifiesta en t1 en el primer apartado, donde hace mención a cuadrados más grandes y más pequeños. En lo relativo a la identificación de los cuadrados, percibe la identificación de los lados paralelos, los segmentos perpendiculares que forman los ángulos de 90 grados y la comparación de áreas. En t2, en cambio, es una constante puesto que al hacer la descripción de la disposición de los cubos y sus caras pintadas, hace referencia a la relación interna que se da entre cada uno de estos objetos.

- Discriminación visual. En t1 la vemos manifestada al discriminar los diferentes conjuntos de cuadrados de acuerdo con sus áreas (“(...) vemos que la cantidad de cuadrados diagonales de área 2 es igual a la cantidad de cuadrados de área 4 (...)”), así como la alusión a "cuadrado grande que encierra la figura" o cuadrados más pequeños", y por último la discriminación del triángulo. En t2 se manifiesta al discriminar los cubitos en función de la relación geométrica existente entre sus caras, agrupándolos por la cantidad de caras pintadas y posteriormente haciendo la distinción de acuerdo con la característica mencionada.

- Memoria visual. Es de destacar que en su versión original, las tareas no requieren de la habilidad denominada como memoria visual. Sin embargo, en el caso de la persona ciega, al no tener acceso a la figura la representación mental que se hace del gráfico de la tarea va a depender en gran medida de cómo conceptualiza cada uno de los elementos geométricos que incluyen los enunciados. En este punto entra en juego dicha habilidad, puesto que es la que le va a permitir a la participante ciega hacer una construcción mental y gráfica de las tareas, teniendo en cuenta el conocimiento previo y aprehensión de los objetos a los que se le está haciendo mención. En otras palabras, la participante ciega debe traer las imágenes mentales que tiene formadas de los objetos cuadrado, línea, paralela, entre otros, para poder relacionarlas con la tarea y en el contexto de la misma llegar a hacerse la representación mental. Esto es especialmente relevante ya que el tacto -medio por el cual el ciego accede a la 
información- a diferencia de la vista, es un sentido que requiere de contacto directo. Esto hace que la información a la que accede la persona ciega se vea reducida en comparación a la que puede acceder su par vidente, restringiendo el conocimiento. Por tanto, si la persona ciega no ha tenido experiencias previas de reconocimiento táctil de los objetos, paso previo a hacerse una imagen mental de los mismos, no podrá hacer una construcción mental de nuevas situaciones en las que deba recordar objetos que no tiene justamente delante.

Esta habilidad es una de las que más destaca (aunque de manera implícita) en ambas tareas. Sin la manifestación de esta característica, no habría sido posible realizar los esquemas expuestos así como la descripción visual que se hizo en t 2 de la disposición de los cubos. En este caso, traer objetos que no tiene justamente delante como cubo de Rubik, cuadrado, líneas paralelas y perpendiculares, entre otras, posibilitó la construcción de nuevas situaciones en las que debió relacionar el conocimiento previo de dichos objetos en el contexto propuesto.

\section{Generalización}

Esta característica se puso de manifiesto en t1 al resolver el caso 100 y N. Observamos que el proceso de generalización se llevó a cabo en estrecha relación con el razonamiento inductivo. Es decir, en primera instancia se trabajó con casos particulares, verificando lo que pasaba una vez transcurrían 3, 4 y 5 días de siembra. Tras este proceso de conteo, los datos fueron organizados en una tabla (ver anexo 4) lo que permitió identificar una regularidad por recurrencia en los casos para el número de cuadrados que llevó a plantear una fórmula de estructura multiplicativa. Una vez identificada la regularidad y el dato invariante, la fórmula general fue planteada sin mucha más explicación. Entendemos que esto se debe a la familiaridad de la participante con este tipo de procesos y la notación algebraica, ya que durante la resolución a la tarea hace alusión a conocimientos anteriores de diferentes fórmulas ya establecidas. De igual manera sucede para el caso de las semillas, en el que también se evidencia uso de pensamiento multiplicativo aunque no recursivo. La organización de los datos en la tabla permitió establecer una relación entre las dos cantidades y la fórmula general fue planteada en función del número de cuadrados. 
En la manifestación de esta característica evidenciamos el uso de dos tipos de representaciones: verbal y simbólica. En general encontramos que las usa de manera conjunta, expresando en primer lugar la generalidad de forma verbal para posteriormente representarla en forma simbólica, la cual parece predominar. No obstante, pudimos encontrar un único fragmento en el que solo se hace uso de la representación verbal. A continuación exponemos la forma en que el proceso de generalización fue representado:

Verbal: En el siguiente fragmento del caso 100 se evidencia uso de representación verbal. Reconoce las variables (los cuadrados de diferente área) y la relación entre ellas, pero sin asignar letras a las mismas.

(...) vemos que la cantidad de cuadrados diagonales de área 2 es igual a la cantidad de cuadrados de área 4 , y que además van aumentando de a 1 por cada día de siembra que transcurre. Podemos concluir fácilmente que restando 2 al número del día en que nos encontramos, obtenemos la cantidad de cuadrados con estas áreas. Por tanto, en el día 100 habrán 98 cuadrados de área 2 y 98 cuadrados de área 4. Esto conlleva a un total de 198 cuadrados de área 1.

(...) vemos que la cantidad de cuadrados diagonales de área 2 es igual a la cantidad de cuadrados de área 4 , y que además van aumentando de a 1 por cada día de siembra que transcurre. Podemos concluir fácilmente que restando 2 al número del día en que nos encontramos, obtenemos la cantidad de cuadrados con estas áreas. Por tanto, en el día 100 habrán 98 cuadrados de área 2 y 98 cuadrados de área 4. Esto conlleva a un total de 198 cuadrados de área 1.

Figura 7. Respuesta al apartado 3 de t1

-Simbólica: Este tipo de representación se manifiesta al generalizar para n el número de cuadrados y la suma del orden de las semillas. Establece para las variables un conjunto de símbolos con los que posteriormente expresa la regularidad detectada. 
Asimismo, se manifiesta al expresar la generalización del número de cuadrados según el área, como se muestra en la figura 9. Allí recurre a conocimiento simbólico previo que le permite encontrar una fórmula general para encontrar la cantidad de cuadrados según el área de los mismos.

Se observa que el número de cuadrados aumenta en un orden de 4 por día, comenzando por 6 . Por tanto, el número de cuadrados me queda representado por la fórmula:

$$
C=4 n-6
$$

Donde $C$ es el número de cuadrados y $n$ el número de día de siembra.

Por otro lado, para la suma del orden de las semillas se observa una relación entre el número de cuadrados y el orden, aumentando en un factor de 4. Por tanto, la suma del orden de las semillas me queda de la siguiente manera:

$$
S=4 C
$$

Donde $S$ es la suma del orden de las semillas y $C$ el número de cuadrados."

Se observa que el número de cuadrados aumenta en un orden de 4 por día, comenzando por 6. Por tanto, el número de cuadrados me queda representado por la fórmula:

$$
C=4 n-6
$$

Donde $C$ es el número de cuadrados y $n$ el número de día de siembra.

Por otro lado, para la suma del orden de las semillas se observa una relación entre el número de cuadrados y el orden, aumentando en un factor de 4. Por tanto, la suma del orden de las semillas me queda de la siguiente manera:

$$
S=4 C
$$

Donde $S$ es la suma del orden de las semillas y $C$ el número de cuadrados."

Figura 8. Respuesta al apartado 4 de t1

\section{4. día n:}

a) La cantidad de cuadrados para el día n la podemos encontrar con la fórmula anterior. Sus áreas, de acuerdo con lo especificado en el punto anterior, las podremos hallar de la siguiente manera:

Para el caso de los cuadrados de área 2 y 4, tendríamos:

$$
C_{2,4}=n-2
$$

Donde $C_{2,4}$ son los cuadrados de área 2 y 4 (habrá la misma cantidad de cada uno) y n el número de días.

Para el caso de los cuadrados de área 1, teniendo en cuenta la fórmula para la cantidad total de cuadrados, bastará con realizar una resta entre ambos resultados para llegar a que dichas áreas las podremos encontrar con la fórmula:

$C_{1}=2 n-2$ 
Donde $C_{1}$ son los cuadrados de área 1 y n el número de días.

a) La suma del orden de las semillas la podemos encontrar con la fórmula mencionada en el apartado anterior.

4. día n:

a) La cantidad de cuadrados para el día n la podemos encontrar con la fórmula anterior. Sus áreas, de acuerdo con lo especificado en el punto anterior, las podremos hallar de la siguiente manera:

Para el caso de los cuadrados de área 2 y 4, tendríamos:

$C_{2,4=} n-2$

Donde $C_{2,4}$ son los cuadrados de área 2 y 4 (habrá la misma cantidad de cada uno) y n el número de días.

Para el caso de los cuadrados de área 1, teniendo en cuenta la fórmula para la cantidad total de cuadrados, bastará con realizar una resta entre ambos resultados para llegar a que dichas áreas las podremos encontrar con la fórmula:

$C_{1}=2 n-2$

Donde $C_{1}$ son los cuadrados de área 1 y n el número de días.

b) La suma del orden de las semillas la podemos encontrar con la fórmula mencionada en el apartado anterior.

Figura 9. Caso n de t1

\subsection{Adaptación de las pruebas}

Con los anteriores resultados y en consonancia con lo reportado en la literatura, encontramos que las dificultades que puede tener un estudiante ciego al resolver una prueba de diagnóstico son meramente de tipo técnico o afectivo. Por esto, las adaptaciones que proponemos están encaminadas a solventar estos dos aspectos, pero manteniendo lo que demanda y evalúa la tarea.

\section{Sembrando semillas}

Como pudo observarse, esta tarea es la que menos modificaciones sufrió en cuanto a su adaptación inicial y en los resultados tampoco se manifiestan situaciones muy diferentes de las que se pueda manifestar al ser resuelta por un vidente. En cuanto a la manifestación de las características del talento asociadas a la generalización que evalúa la tarea, encontramos que: 
a) Localiza la clave de los problemas al reconocer el número de cuadrados según el área que se añaden tras cada día de siembra, pudiendo contabilizar.

b) Organiza los datos haciendo uso de una representación adecuada (tabla) que le permite llevar un conteo sistemático de los cuadrados según el tamaño y posición y

c) Relaciona el proceso con otros patrones conocidos, lo que le permite relacionar la representación numérica, simbólica y geométrica de las áreas de los cuadrados. De esta manera formula una expresión con la que puede hallar la cantidad de cuadrados con sus respectivas áreas.

De acuerdo con lo anterior, podemos postular que la versión modificada de la tarea no cambió las características que evalúa el enunciado original. Sin embargo, en el proceso de resolución hubo algunos inconvenientes de tipo técnico que pueden ralentizar su resolución. Por ejemplo, la realización de los diferentes dibujos conlleva un tiempo adicional para la persona ciega, ya que en general es un punto en el que no se hace mucho énfasis en su educación. Por otro lado, a medida que van aumentando los días y por tanto los cuadrados, el interior de la figura se ve más saturado y se torna complejo distinguir al tacto los lados correspondientes a cada uno, especialmente los que están apoyados sobre su vértice. Esto también hace que se deban mantener muchos datos de manera mental a la hora del recuento de las semillas.

Además, como mencionábamos en el capítulo de antecedentes, el acceso a la información por parte de la persona ciega puede hacerse a través del braille o de manera digital con el apoyo de lectores de pantalla. Por tanto, consideramos que la adaptación de esta tarea consiste en facilitarle a la persona ciega el texto en braille o en digital, en ambos casos acompañados por la figura que presenta el enunciado en relieve para que sirva como punto de partida para sus dibujos. Sobre este último punto y de acuerdo con lo mencionado anteriormente, habría que considerar una adaptación en el tiempo que se da para la resolución de la prueba atendiendo a estos aspectos técnicos. Con estas modificaciones, consideramos que la tarea conserva las características que evalúa en su versión original y solo cambia la vía de acceso a la información. 


\section{Pintando cubos y cubitos}

Debido al componente visual esta tarea es la que mayor adaptación requiere. En la versión inicial decidimos hacerlo a partir de la descripción de las imágenes, pero como se evidencia en el análisis anterior, esto agrega un esfuerzo adicional para el estudiante ciego que se esté examinando. Además, la forma en que se expone el texto y la imagen en el enunciado debería ser secuencial, correspondiéndose uno a uno ya que lo contrario genera confusión. Al ser todo textual no hay cabida a las orientaciones que hagan referencia a la ubicación de la imagen (izquierda, derecha, etc.) y por tanto en el enunciado estas referencias deberían ser eliminadas y hacer corresponder la descripción de la imagen con lo que se menciona en el texto.

Adicionalmente, vemos en la resolución una dificultad para realizar los esquemas correspondientes, puesto que en general los estudiantes ciegos no están acostumbrados a realizar dibujos en el plano de objetos en tres dimensiones y no tienen la perspectiva de ello. Esta es una habilidad que el estudiante vidente aprende de sus experiencias educativas y visuales, de manera que si al estudiante ciego no se le fuerza a ello o se le enseña difícilmente sabrá hacerlo por la falta de instrucción. Por lo anterior, consideramos que la adaptación en este caso puede hacerse a través de material manipulativo, de tal manera que las figuras que acompañan el enunciado sean presentadas en tres dimensiones. No obstante, esta modificación conlleva la pérdida de la manifestación de ciertas habilidades. Por ejemplo, la habilidad de contar a partir de la representación visual (que implica imaginarse caras no visibles) se sustituiría por un conteo físico, en lo que ciertas habilidades de la visualización no se ponen en juego. Es decir que si no se usa material, la tarea se torna mucho más compleja para la persona con discapacidad visual, pero si se usa, se sustituyen habilidades por otras estrategias. Por ejemplo, la tarea también demanda una adecuada y eficiente acomodación de los cubitos según lo que pide cada apartado. Esto implica la puesta en juego de distintas habilidades de visualización que no se estarían viendo modificadas, mientras que el conteo tiene una relación directa de dependencia con esta acomodación. Además, estas habilidades se manifiestan en la descripción que hace el estudiante del proceso, por lo que igualmente sería posible su evaluación. 


\section{CONCLUSIONES}

En esta investigación describimos las características asociadas a la generalización y el sentido espacial que se demandan en dos tareas seleccionadas de la prueba ESTALMAT. De igual manera, describimos las características puestas en juego por una persona con discapacidad visual al resolverlas, y con base en estos dos resultados propusimos una posible adaptación para que estas tareas puedan ser resueltas por estudiantes ciegos manteniendo las características que evalúan.

\subsection{Logro de objetivos de investigación}

En el análisis de las tareas, encontramos que ambas demandan características relativas al sentido espacial y habilidades de visualización. Sobre este punto, destacamos la diferencia que encontramos entre las características que demanda la tarea y las que son puestas en juego en la resolución, como sucede en el caso de la habilidad relativa a la percepción de relaciones espaciales. Esto hace que haya un contraste entre los resultados encontrados en Aznarte (2018) quien destaca la ausencia de referencias a cuestiones relacionadas con componente ubicación

y movimientos, mientras que nosotros la encontramos en la habilidad para imaginarlos en la resolución que propone la participante para la tarea 2.

En la misma línea destacamos lo que sucede con la habilidad referida a memoria visual, la cual, de acuerdo con Aznarte (2018) no se evalúa en la prueba. Sin embargo, encontramos que juega un papel fundamental tanto en la versión adaptada de las tareas como en la resolución, ya que sin ésta la persona ciega no podría hacerse la representación mental de las descripciones que se le proponen. Sobre este punto destacamos que al tratarse de una participante que adquirió la ceguera desde una edad muy temprana, las construcciones visuales que trae son reconocimientos táctiles que ha hecho de los objetos. Esto, de acuerdo con Figueiras y Arcabi (2013) no impide la visualización. De hecho, los resultados de nuestro trabajo están en consonancia con lo que los autores encuentran en su estudio, pues al parecer los recursos lingüísticos como las metáforas visuales, actuaron como un componente esencial en la representación de las diferentes ideas geométricas que se presentaron en las tareas. 
Por otro lado, a diferencia de lo observado en la tarea 1, en la tarea 2 la resolución se dio en su totalidad de forma verbal. Esto nos hace pensar que hay una dificultad con la realización de esquemas en tres dimensiones, lo que tiene su explicación no en la ceguera como tal, sino en la falta de preparación al respecto (Fernández, 1995; Thinus-Blanc y Gaunet, 1997; Rosenblum y Herzberg, 2015; Viginheski et al., 2016). Lo anterior también se debe, por un lado, a la dificultad adicional que conlleva la ceguera total temprana al recoger, procesar y almacenar información de tipo figurativo o espacial (Pérez-Ruiz, S.F); y por otro, a las pocas tareas sobre orientación y visualización de espacios y objetos tridimensionales que se localizan en libros de texto y por consiguiente la poca importancia que se le da en las aulas (Gonzato, et al., 2011). Esta falencia que es detectada en un contexto de aula regular, en la que de acuerdo con el modelo educativo actual también se encuentran incluidos los estudiantes ciegos, los afecta de manera particular si tenemos en cuenta el escaso trabajo que se hace con esta población en relación con figuras geométricas, objetos en tres dimensiones y el estudio de su orientación y visualización reportado en múltiples investigaciones. Esto conlleva un retraso en el desarrollo de dichas habilidades y por tanto en la resolución de tareas basadas en éstas.

Asimismo, las autoras Thinus-Blanc y Gaunet (1997), destacan el papel fundamental de la visión en el desarrollo de las diferentes habilidades espaciales, pero exponen varios experimentos en los que se observa una falta de consenso con respecto a la influencia de la privación visual temprana en el desempeño de tareas espaciales. En consonancia con nuestros resultados, destacamos los resultados que se encontraron con respecto a la variación en el experimento en los que no se observaron diferencias con respecto a la habilidad para representar y manipular mentalmente los objetos entre ciegos y videntes, pero sí en los tiempos de la realización de los dibujos.

En lo relativo a la generalización se evidencia el uso de representaciones verbal y simbólica, con predominancia de esta última probablemente como consecuencia del nivel formativo de la participante (Pinto y Cañadas, 2019; Ureña et al., 2019, en revisión). Al igual que Zazkis y Liljedahl (2002), encontramos que la participante detectó similitudes y diferencias, buscó algoritmos, estableció relaciones numéricas entre componentes, entre otras 
actividades propias del pensamiento algebraico (Mason, 1996) y Kaput (1999). Aunque el foco de nuestro trabajo no fue sobre las estrategias que se emplean, sí llama la atención que el papel que parece otorgarle la participante al dibujo en el proceso de abstracción y generalización es en el doble sentido que exponen García-Cruz y Martinón (1996), pues lo utiliza tanto como estrategia visual para obtener datos, como medio para dar validez a la respuesta. Este aspecto genera interés al tratarse de una participante ciega, de la cual a priori no se esperarían estrategias visuales, sin embargo vemos que las favorece. No obstante, al avanzar en el proceso de generalización opta por un enfoque analítico, coincidiendo con lo expuesto por Barbosa et al. (2012). Al generalizar la fórmula para encontrar cuántos cuadrados habría de cada área, su razonamiento se apoya en una diferencia de expresiones algebraicas que previamente había formulado (ver figura 9).

Estos resultados constatan lo que nos aventuramos a formular en el capítulo de antecedentes, y es que la ceguera no es una condición que aminore las capacidades cognitivas en el proceso de generalización. Las dificultades que puedan encontrarse, al igual que en el caso de estudios con participantes videntes, pueden deberse a múltiples factores educativos, sociales o personales. Tal como fue mostrado en el estudio de Viginheski et al. (2014b), los estudiantes ciegos pueden desarrollar procesos como búsqueda de patrones, pensamiento lógico, organización de datos, entre otros, todos ellos procesos que favorecen la generalización.

Con todo lo anterior damos respuesta a los objetivos específicos que nos planteamos. Particularmente, en relación con el segundo objetivo en el que nos proponíamos hacer un contraste con las características inicialmente demandadas, destacamos el resultado en el que encontramos que la persona ciega debe poner en juego muchas más habilidades relativas al sentido espacial y la visualización para la resolución de las tarees, particularmente las relativas a la componente "ubicación y movimientos" y la habilidad "memoria visual". En esta misma línea están los resultados expuestos por Viginheski et al. (2014ª) quienes reportaron que la adaptación de una pregunta hecha meramente como una descripción verbal puede tornar la pregunta bastante más abstracta y compleja para la persona ciega. 
Por lo anterior y con el fin de dar respuesta al tercer objetivo específico, planteamos una adaptación de la prueba en la que se mantuvieran las características que evalúan las tareas pero en igualdad de condiciones para los participantes. Para ello tuvimos en cuenta las recomendaciones de Stylianidou y Nardi (2019), quienes señalan algunas limitaciones en las adaptaciones que se hacen para personas ciegas. En este sentido, propusimos una adaptación en la que se tenga en cuenta la preferencia del estudiante en el medio de información (digital o braille) entendiendo que en el caso del primero habría que asegurarse de que las fórmulas sean accesibles con el lector de pantalla, es decir que puedan ser traducidas correctamente a voz; y en el caso del segundo verificar que no haya errores o elementos faltantes antes de la entrega de la impresión braille al estudiante. En ambos casos, las imágenes que incluye la tarea deben ser presentadas en relieve atendiendo a las recomendaciones hechas por los mismos autores y por Neves y Maia (2018), Rosenblum y Herzberg (2015) y Viginheski et al. (2014a) (ver por ejemplo figura 13 en ANEXO 2).

Particularmente, para el caso de la tarea 2 que incluye esquemas de objetos en tres dimensiones, es importante tener en cuenta las recomendaciones de Viginheski et al., (2014 $\left.{ }^{\mathrm{a}}\right)$ quienes señalan que las representaciones de tales objetos no proporcionan la misma información desde una percepción háptica que desde una percepción visual. Por ello, invitan a utilizarlas con reserva y a que sean acompañadas con información verbal. No obstante, de acuerdo con la experiencia de la autora de la investigación y con las diferentes investigaciones citadas más arriba donde se subraya la falta de preparación que tienen estos estudiantes en el reconocimiento de representaciones bidimensionales de objetos en tres dimensiones, sugerimos el uso de material manipulativo con un tamaño y textura adecuados para su correcto reconocimiento. Consideramos que esta adaptación no impide la evaluación de las características que demanda la tarea y más bien elimina la complejidad extra que encontramos que tiene la versión adaptada solo de forma verbal en nuestra investigación.

Por último, destacar que, de acuerdo con los resultados, las características del talento matemático y de manera particular las asociadas al sentido espacial y la generalización, pueden ser manifestadas por estudiantes ciegos al igual que por estudiantes videntes. Sin llegar a hacer un diagnóstico como tal, en la resolución de las tarees vimos manifestadas 
características como habilidad para organizar datos, localizar la clave de los problemas, buscar patrones y relaciones, construir nexos, lazos y estructuras matemáticas, cambiar fácilmente de una estrategia o estructura a otra, y finalmente habilidad para generalizar y trabajar de forma abstracta viendo relaciones entre objetos matemáticos (ver tabla 1).

No obstante, en relación a su identificación y de acuerdo con los estudios de Lopes y Gil (2016), Rangni y Costa (2016), Starr (2003) y Viginheski et al. (2016), encontramos que una de las desventajas que existen actualmente es la falta de instrumentos adecuados. consideramos que con nuestra investigación no solo contribuimos al reconocimiento de estas habilidades, sino a la deficiencia de pautas en la literatura para identificar a estudiantes ciegos con talento y en particular el matemático, así como al vacío que hay en la intersección de estudios relacionados con discapacidad visual y talento matemático.

\subsection{Limitaciones del estudio y vías de continuidad}

Tenemos una clara limitación en el estudio y es el hecho de que se trate de una sola participante así como las características de la misma. El nivel y tipo de formación de la participante hace que haya tenido cercanía con experiencias que la mayoría de estudiantes ciegos en una etapa escolar no han tenido, y por tanto los resultados obtenidos no son susceptibles de ser generalizados a toda la población ciega. Por la misma razón, habría sido interesante contar con un mayor número de participantes y con diferente nivel formativo para poder generar un contraste de resultados que permitiera analizar posibles relaciones de causalidad.

En este sentido, son múltiples las vías de continuidad que quedan abiertas:

-La réplica de este estudio con un número mayor de participantes ciegos y de otro nivel formativo.

-En relación con la anterior, un estudio en el que se comparen los resultados obtenidos por estudiantes ciegos y estudiantes videntes aplicando la adaptación que hicimos a la tarea dos para todos, analizando qué aspectos cambian en la manifestación de las características en el caso de los videntes (contraste con otros estudios). 
-Un estudio con participantes ciegos en el que se evalúen tarees con otro tipo de características demandadas para su comparación y así poder contrastar el desempeño en tarees relacionadas con el sentido espacial y la visualización y aquellas que no requieren de su activación.

-Y por último, una investigación en la que se comparen los resultados obtenidos en una prueba de diagnóstico de talento matemático presentada por estudiantes ciegos y videntes previamente postulados por sus padres o profesores. 


\section{REFERENCIAS}

Aznarte, M. (2018). Análisis del sentido espacial en una prueba de acceso a un programa de estimulación del talento matemático (Trabajo fin de Máster). Universidad de Granada.

Barbosa, A., Vale, I. y Palhares, P. (2012). Pattern tasks: Thinking processes used by 6th grade students. Revista Latinoamericana de Investigación en Matemática Educativa, 15(3), 273293.

Bishop, A. J. (1983). Space and geometry. En R. Lesh y M. Landau (Eds.), Acquisition of mathematics concepts and processes (pp. 175-203). Academic Press.

Borges, F., Da Silva, S. C. R. y VIGINHESKI, L. V. M. (2018). Produçoes técnicas para o ensino de geometria para alumnos com deficiência visual: estado da arte. VI Simpósio Nacional de Ensino de Ciência e Tecnologia SINECT, 1, 1-10.

Cañadas, M. C. y Castro, E. (2007). A proposal of categorisation for analysing inductive reasoning. PNA, 1(2), 67-78.

Cañadas, M. C., Castro, E. y Castro, E. (2007). Patrones, generalización y estrategias inductivas de estudiantes de $3^{\circ}$ y $4^{\circ}$ de la ESO en el problema de las baldosas. En M. Camacho, P. Flores y P. Bolea (Eds.), Investigación en Educación Matemática XI (pp. 283-294). SEIEM.

Carraher, D., Martínez, M., \& Schliemann, A. (2008). Early Algebra and mathematical generalization. ZDM Mathematics Education, 40, 3-22.

Castro, E., Cañadas, M. C. y Molina, M. (2010). El razonamiento inductivo como generador de conocimiento matemático. UNO: Revista de Didáctica de la Matemática, 54, 55-67.

Clements, D. H. y Battista, M. T. (1992). Geometry and spatial reasoning. En D. A. Grouws (Ed.), Handbook of research on mathematics teaching and learning: A project of the National Council of Teachers of Mathematics (pp. 420-464). Macmillan.

Colangelo, N. y Davis, G. (2008). Handbook of gifted education. Allyn and Bacon. 
Congreso de la República de Colombia. (1994, 8 de febrero). Ley 115. Por la cual se expide la ley general de educación. Diario oficial 41214. https://bit.ly/3237N87

Cornoldi, C., Cortesi, A., y Preti, D. (1991). Individual differences in the capacity limitation of visuo-spatial short-term memory: Research on sighted and totally congenitally blind people. Memory and Cognition, 19, 459-468.

Del Grande, J. J. (1987). Spatial perception and primary geometry. En M. M. Lindquist (Ed.), Learning and Teaching Geometry, K-12 (pp. 127-135). National Council of Teachers of Mathematics.

Del Grande, J. J. (1990). Spatial sense. Arithmetic Teacher, 37(6), 14-20.

Delors, J. (1996). La educación encierra un tesoro. Informe a la UNESCO de la Comisión Internacional sobre Educación para el siglo XXI. Santillana, UNESCO.

Fernández, J. E. (1995). La enseñanza de la matemática a los ciegos. Organización Nacional de Ciegos Españoles (ONCE).

Figueiras, L. y Arcavi, A. (2013). A touch of mathematics: Coming to our senses by observing the visually impaired. ZDM-The International Journal on Mathematics Education, 46(1), $123-133$.

Flores, P., Ramírez, R. y Del Río, A. (2015). Sentido espacial. En P. Flores y L. Rico (Eds.), Enseñanza y aprendizaje de las matemáticas en educación primaria. Pirámide.

Freiman, V. (2006). Problems to discover and to boost mathematical talent in early grades: A challenging situations approach. The Montana Mathematics Enthusiast, 3(1), 51-75.

García Cruz, J. A. y Martinón, A. (1997). Actions and invariant schemata in linear generalizing problems. En E. Pehkonen (Ed.), Proceedings of the 21st Conference of the International Group for the Psychology of Mathematics Education (Vol. 2, pp. 289-296). Universidad de Helsinki y PME.

Gonzato, M., Fernández, T. y Díaz, J. (2011). Tareas para el desarrollo de habilidades de visualización y orientación espacial. Números. Revista de Didáctica de las Matemáticas, 77, 99-117.

Greenes, C. (1981). Identifying the gifted student in mathematics. Arithmetic Teacher, 28(8), 14-17. 
Gruessing, M. (2011). Spatial abilities and mathematics achievement among elementary school children. En B. Ubuz (Ed.), Proceedings of the 35th Conference of the International Group for the Psychology of Mathematics Education (Vol. 1, p. 306). PME.

Gutiérrez, A. (1996). Visualization in 3-dimensional geometry: In search of a framework. En L. Puig y A. Gutiérrez (Eds.), Proceedings of the 20th PME Conference (Vol. 1, pp. 3-19). Universidad de Valencia y PME.

Hershkowitz, R. (1990). Psychological aspects of learning geometry. En P. Nesher y J. Kilpatrick (Eds.), Mathematics and cognition (pp. 70-95). Cambridge University Press.

Hernández, M. (2015). El concepto de discapacidad: de la enfermedad al enfoque de derechos. Revista. CES Derecho, 6 (2), 46-59.

Hernández, R., Fernández, C. y Baptista, P. (2007). Fundamentos de metodología de la investigación. McGraw Hill.

Hoffer, A. R. (1977). Mathematics resource project: Geometry and visualization. Creative Publications.

Human, P. G. (1998). Draft discussion document for Malati Geometry Working Group. Cape Town, South Africa.

Kaput, J. (1999). Teaching and learning a new algebra. En E. Fennema y T. A. Romberg (Eds.), Mathematics classrooms that promote understanding (pp. 133-155). Lawrence Erlbaum Associates.

Klingenberg, O. G., Holkesvik, A. H. y Augestad, L. B. (2019). Research evidence for mathematics education for students with visual impairment: A systematic review. Cogent Education, 6(1). https://www.tandfonline.com/doi/full/10.1080/2331186X.2019.1626322

Krutetskii, V. A. (1976). The psychology of mathematical abilities in school children. University of Chicago Press.

Lean, G. y Clements, M. A. (1981). Spatial ability, visual imagery, and mathematical performance. Educational Studies in Mathematics, 12(3), 267-299.

Lederman, S. J., y Klatzky, R. L. (2009). Haptic perception: A tutorial. Attention, Perception and Psychophysics, 71(7), 1439-1459. 
Lee, K., Ko, E. y Song, S. (2007). The analysis of activity that gifted students construct definition of regular polyhedra. En J. H. Wo., H. C. Lew, K. S. Park y D. Y. Seo (Eds.), Proceedings of the 31st Conference of the International Group for the Psychology of Mathematics Education (Vol. 3, pp. 153-160). PME.

Llamazares, J., Arias, A. y Estrada, M. (2019). Theorical review of the teaching of mathematics in student with visual functional diversity. TEEM'19: Proceedings of the Seventh International Conference on Technological Ecosystems for Enhancing Multiculturality. Universidad de León. https://doi.org/10.1145/3362789.3362806.

Lopes, B. J. y Coutinho, M. E. (2016). Altas habilidades/superdotação percebidas pelas mães nos seus filhos com deFiciência visual. Revista Brasileira de Educação Especial, 22(2) 203-220.

Mason, J. (1996). Expressing generality and roots of algebra. En N. Bednarz, C. Kieran y L. Lee (Eds.), Approaches to algebra perspectives for research and teaching (pp. 65-86). Kluwer.

Mason, J., Burton, L. y Stacey, K. (1989). Thinking mathematicaly. Labor.

Miller, R. C. (1990). Discovering mathematical talent. ERIC Digest E482. Office of Educational Research and Improvement.

Molina, M. C. (1999). Integración del invidente en la clase de matemáticas: un estudio comparado de videntes e invidentes (Tesis Doctoral). Universidad de Zaragoza.

Muñoz, A. (2010). Discapacidad: contexto, concepto y modelos. Internacional Law, Revista Colombiana de Derecho Internacional, 16, 381-414.

National Council of Teachers of Mathematics (2000). Principios y estándares para la educación matemática. SAEM THALES.

NCTM (1989). Curriculum and EvaluationStandards for School Mathematics. National Council of Teachers of Mathematics.

NCTM (2003). Principios y estándares para la Educación Matemática. Autor y Sociedad Andaluza de Educación Matemática Thales.

Neria, D. y Amit, M. (2010). Talented middle school students's strategies and reasoning in solving analytic reasoning problems. En M. M. Pinto, F. Pinto y T. F. Kawasaki (Eds.), 
Proceedings of the 34th Conference of the International Group for the PME (Vol. 3, pp. 321-328). PME.

Neves, C. N. y Maia, R. M. C. S. (2018). O uso de materiais adaptados para o ensino da matemática para estudantes com deficiência visual. Boletim Online de Educação Matemática, 6(11), 119-137.

OCDE (2021, 25 de enero). Estudiantes con discapacidades, dificultades y desventajas - Estadísticas e indicadores para acceso al currículo y equidad (necesidades educativas especiales) en los países de la Organización de los Estados Americanos (OEA). https://cutt.ly/3j1u6fz

Organización de las Naciones Unidas (2007). Convención sobre los derechos de las personas con discapacidad. Sección de reproducción de Naciones Unidas.

Organización Mundial de la Salud (2012). Change the definition of blindness. Definitions of blindness and visual impairment. Autor.

Organización Mundial de la Salud (2013). Salud ocular universal: un plan de acción mundial para 2014-2019. Autor.

Passow, A. (1993). National/State policies regarding education of the gifted. En K. Séller, F. Mönks y A. Passow (Eds.), Internacional handbook of research and development of giftedness and talent (pp. 29-46). Pergamon Press.

Pérez Ruiz, C. (s.f.) La respuesta educativa a los estudiantes con discapacidad visual. Fundación Mapfre. https://www.fundacionmapfre.org/fundacion/es_es/images/inclusion-respuestas-discapacidad-visual_tcm1069-242565.pdf

Piaget, J. (1975). Introducción a la epistemología genética. Tomo II. Paidós.

Pitta-Pantazi, D. y Christou, C. (2009). Psychological aspect: Identification of giftedness in earlier ages. En M. Tzekaki, M. Kaldrimidou y H. Sakonidis (Eds.), Proceedings of the 33 rd Conference of the International Group for the Psychology of Mathematics Education (Vol. 1, pp. 191-194). PME.

Pinto, E. y Cañadas, M. C. (2019). Generalizations of third and fifth graders within a functional approach to early algebra. Mathematics Education Research Journal. https://doi.org/10.1007/s13394-019-00300-2 
Pólya, G. (1967). La découverte des mathématiques. DUNOD.

Pólya, G. (1989). ¿Cómo plantear y resolver problemas? Trillas.

Presmeg, N. C. (1986). Visualisation and mathematical giftened. Educational Studies in Mathematics, 17(3), 297-311.

Rabab'h, B. y Veloo, A. (2015). Spatial visualization as mediating between mathematics learning strategy and mathematics achievement among 8th grade students. International Education Studies, 8(5), 1-11.

Radford, L. (2008). Iconicity and contraction: a semiotic investigation of forms of algebraic generalizations of patterns in different contexts. The International Journal on Mathematics Education (ZDM), 40(1), 83-96. https://doi.org/10.1007/s11858-007-0061-0

Ramírez, R. (2012). Habilidades de visualización de los alumnos con talento matemático. (Tesis doctoral). Universidad de Granada.

Rangni, R. y Costa, A. (2016). Altas habilidades/superdotação e deficiência visual: duplicidade de necessidades educacionais especials. Revista Ibero-Americana de Estudos em Educação, 11(4) 1979-1993.

Reid, D. (2002). Conjectures and refutations in grade 5 mathematics. Journal for Research in Mathematics Education, 33 (1), 5-29.

Reily, L. (2004). Escola inclusiva: linguagem e mediação. Papirus.

Ripollés, M. T. (2008). La discapacidad dentro del enfoque de capacidad y funcionamientos de Amartya Sen. Araucaria. Revista Iberoamericana de Filosofía, Política y Humanidades, 10(20), 64-94.

Rivera, F. D. (2011). Towards a visually-oriented school mathematics curriculum. Springer.

Rosenblum, L. P. y Herzberg, T. S. (2015). Braille and tactile graphics: Youths with visual impairments share their experiences. Journal of Visual Impairment \& Blindness, 109(3), 173-184. https://doi.org/10.1177/0145482X1510900302

Ryu, H. Chong, Y. y Song, S. (2007). Mathematically gifted students' spatial visualization ability of solid figures. En J. H. Wo., H. C. Lew, K. S. Park y D. Y. Seo (Eds.), Proceedings of the 31st Conference of the International Group for the Psychology of Mathematics Education, (Vol. 4, pp. 137-144). PME. 
Shimazaki, E. M., Da Silva, S. C. R. y Viginheski, L. V. M. (2015). O ensino da Matemática e a diversidade: o caso de uma estudante com deficiência visual. Interfaces da Educação, 6(18), 148-164. https://periodicosonline.uems.br/index.php/interfaces/article/view/ $1082 / 913$

Stacey, K. (1989). Finding and using patterns in linear generalising problems. Educational Studies in Mathematics, 20(2), 147-164.

Starr, R. (2003). Show me de light - I can't see how bright I am: gifted students with visual impairment. En D. Montgomery (Ed.), Gifted and talented children with special educational needs: double exceptionality (pp. 93-109). David Fulton Publishers.

Stylianidou, A. y Nardi, E. (2019). Tactile construction of mathematical meaning: Benefits for visually impaired and sighted pupils. En M. Graven, H. Venkat, A. Essien y P. Vale (Eds.), Proceedings of the 43rd Conference of the International Group for the Psychology of Mathematics Education (Vol. 3, pp. 343-350). PME.

Thinus-Blanc, C. y Gaunet, F. (1997). Representation of space in blind persons: Vision as a spatial sense? Psychological Bulletin 121(1), 20-42.

UNESCO (1994) Informe Final. Conferencia mundial sobre necesidades educativas especiales: acceso y calidad. UNESCO/Ministerio de Educación y Ciencia. https://sid.usal.es/idocs/F8/FDO1005/6.1.3.4-1005.pdf

Ureña, J., Ramírez, R. y Molina, M. (2019). Representations of the generalization of a functional relationship and the relation with the interviewer's mediation. Infancia y Aprendizaje, 42(3), 570-614.

Ureña, J., Ramírez, R., Cañadas, M. y Molina, M. (en revisión). Estrategias y expresiones de generalización de estudiantes de último curso de primaria y primeros cursos de secundaria en un contexto funcional.

Vale, I. (2010). From figural growing patterns to generalization: Apath to algebraic thinking. En Pinto, M. F. y Kawasaki, T.F. (Eds.), Proceedings of the 34th Conference of the International Group for the Psychology of Mathematics Education (Vol. 4, pp. 241-248). PME. 
Van Garderen, D. (2006). Spatial visualization, visual imagery, and mathematical problem solving of students with varying abilities. Journal of Learning Disabilities, 39(6), 496506.

Van Garderen, D. y Montague, M. (2003). Visual-Spatial representation, mathematical problem solving, and students of varying abilities. Learning Disabilities Research \& Practice, $18(4), 246-254$.

Viginheski, L. V. M. (2004). Vestibular: o desafio da inclusão na exclusão. Analecta, 5(2) 3842.

Viginheski, L. V. M., Frasson, A. C., da Silva, S. C. R. y Shimazaki, E. M. (2014a). O sistema Braille e o ensino da Matemática para pessoas cegas. Ciência \& Educação, 20(4), 903916.

Viginheski, L. V. M., Souza, A., da Silva, S. C. R. y Lima, S. A. (2014b). O uso da torre de Hanoi para formação de conceitos matemáticos com pessoas com deficiência visual. En IV SINECT - Simpósio Nacional de Ensino de Ciência e Tecnologia, Anais do IV SINECT. Ponta Grosa, Brasil.

Viginheski, L. V. M., Souza, A. E., da Silva, S. C. R. y Shimazaki, E. M. (2016). Uma análise do desempenho de estudantes cegos de um municipio do interior do Paraná na olimpíada brasileira de matemática das escolhas públicas - OBMEP. En: V SINECT - Simpósio Nacional de Ensino de Ciência e Tecnologia, Anais do V SINECT. Ponta Grosa, Brasil.

Zazkis, R. y Liljedahl, P. (2002). Generalization of patterns: The tensión between algebraic thinking and algebraic notation. Educational Studies in Mathematics, 49, 379-402

\section{ANEXOS}

\section{ANEXO 1: OLIMPIADAS BRASILEÑAS OBMEP}

Alice hizo tres pliegues en una hoja de papel cuadrada de $20 \mathrm{~cm}$, blanca por delante y gris por detrás. En el primer pliegue, hizo coincidir un vértice con el centro del 
cuadrado y luego hizo dos pliegues más, como se muestra en la figura. Después del tercer pliegue, ¿cuál es el área de la parte gris de la hoja que es visible?

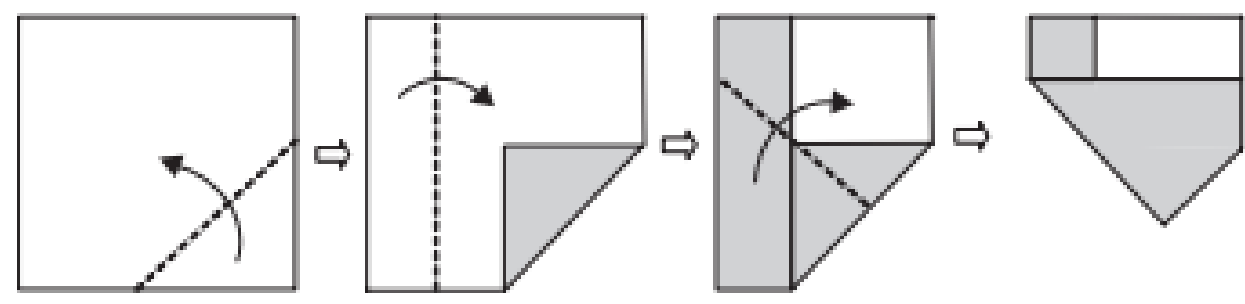
A) $70,5 \mathrm{~cm}^{2}$
B) $100,5 \mathrm{~cm}^{2}$
C) $112,5 \mathrm{~cm}^{2}$
D) $162,5 \mathrm{~cm}^{2}$
E) $225,5 \mathrm{~cm}^{2}$

Figura 10. Pregunta 11, Nivel 1, OBMEP. Fuente. Viginheski, et al. (2016), p. 9

En la prueba en braille (OBMEP, 2016 a, p. 24), las imágenes fueron adaptadas en relieve acompañadas de puntos de referencia destacadas en las descripciones a seguir.| Nota de transcripción: Las partes grises de las figuras siguientes están representadas con el símbolo "é".

Usando un segmento $P Q$ como pliegue, lleva el punto $B$ al punto $O$, aparece el triángulo gris $O P Q$. Lleva el punto A al punto $P$, de modo que el segmento $O P$ se apoye en el lado del anuncio; el pliegue pasa por un punto $M$ en el lado AP y un punto $N$ en el lado DC. Aparecen un rectángulo AMND gris y un cuadrado ODCQ blanco. Conduce el punto A al punto $Q$, a través de un pliegue que pasa por un punto $R$ en el segmento $A Q$ y un punto $S$ en el segmento $M N$, el segmento $R S$ pasa por $O$.

Aparece un cuadrilátero AMSR gris con $\mathrm{O}$ en el lateral MS, un cuadrado ODNS gris y un rectángulo ODCM blanco

Figura 11. Adaptación pregunta 11, Nivel 1, OBMEP. Fuente. Viginheski, et al. (2016), p. 9 
ANEXO 2: PRUEBA DE SELECTIVIDAD

En la figura de arriba, las rectas $r \mathrm{y}$ t son perpendicu-
lares $y \mathrm{~A}=(2,0)$. Las ecuaciones de la recta r y de la
recta que es paralela a t $y$ pasa por el origen son, res-
pectivamente, iguales a:
A) $3 x-\sqrt{3} y+\sqrt{3}=0$ e $y=\sqrt{3} x$
B) $\sqrt{3} x-3 y+6 \sqrt{3}=0$ e $y=-\sqrt{3} x$
C) $\sqrt{3} x-3 y-6 \sqrt{3}=0$ e $\sqrt{3} y=-x$
D) $3 x-3 y+\sqrt{3}=0$ e $\sqrt{3} y=x$
E) $\sqrt{3} x-3 y+6 \sqrt{3}=0$ e $y=-3 x$
MAT-18 -36

Figura 12. Pregunta de selectividad.

Fuente: Viginheski et al. (2014). Traducción libre de la autora 


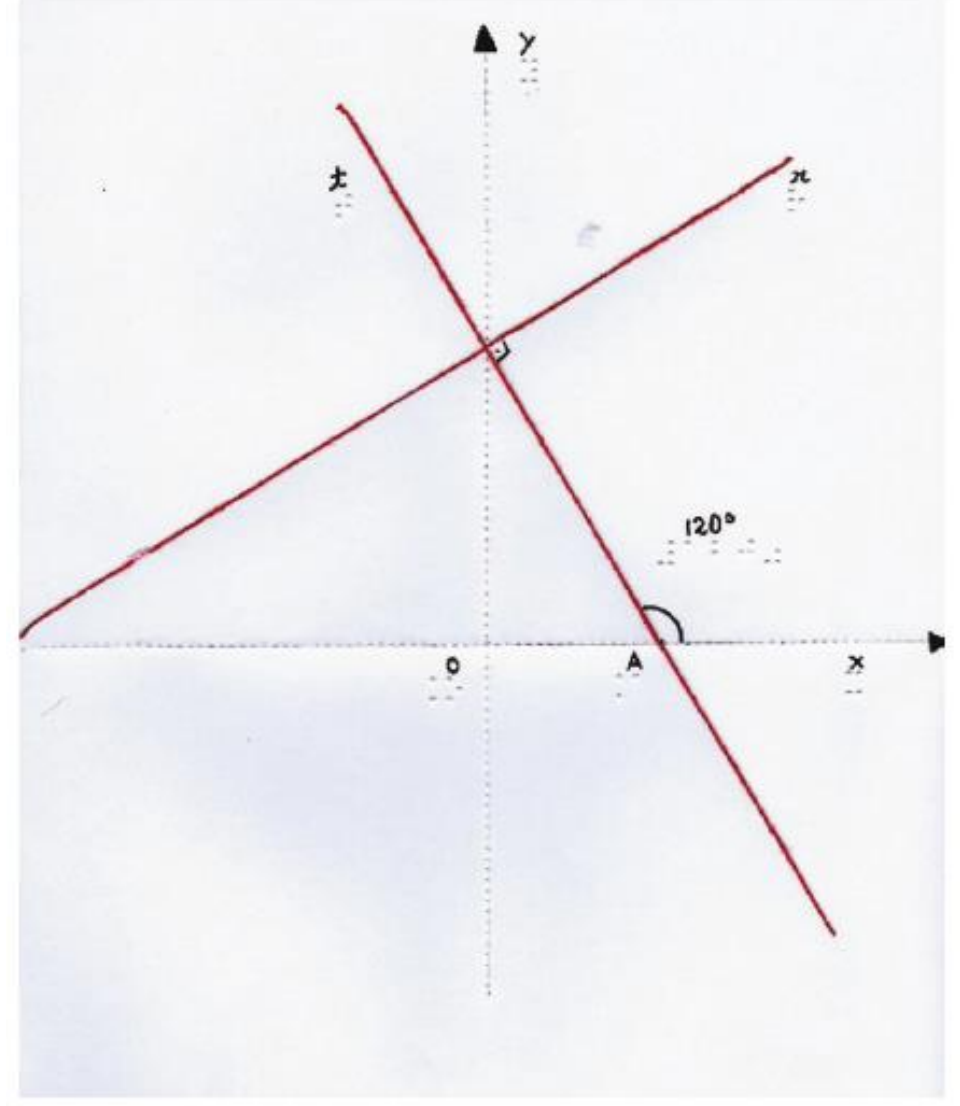

Figura 13. Adaptación en relieve. Fuente: Viginheski et al. (2014), p. 911

\section{ANEXO 3: ANÁLISIS DE LAS TAREAS PREVIO A LA ADAPTACIÓN}

En este apartado realizaremos un análisis de las dos tareas seleccionadas de la prueba ESTALMAT para nuestra investigación, subrayando las características que son demandadas en ellas.

\section{Tarea 1: Sembrando Semillas}

Esta tarea ha sido ampliamente revisada por Cañadas y Ramírez (2018). Su enfoque principal es la generalización en el ámbito de las relaciones funcionales. La función lineal que relaciona el número de días y el número de cuadrados es n=4x-6. 
No obstante, dado que la tarea está estructurada para llegar a la generalización a través de un proceso inductivo, para la resolución de los primeros dos apartados no se requiere de habilidades de generalización. En cambio, solo se deben poner en juego habilidades relacionadas con el sentido espacial y la visualización: por un lado la componente de elementos geométricos, puesto que el enunciado incluye varios conceptos que el estudiante debe conocer para entender el planteamiento, como por ejemplo línea recta, cuadrado, vértice; así como el conocimiento de las propiedades del cuadrado. Por otro lado, entra en juego la componente de relaciones geométricas al incluir en el planteamiento relaciones como líneas paralelas, ángulos rectos, igualdad de medidas. Asimismo, puesto que la tarea requiere determinar la cantidad de cuadrados que se forman con las semillas distribuidas en una cuadrícula como vértices, se ponen en juego habilidades de visualización tales como percepción figura-contexto, percepción de las relaciones espaciales y discriminación visual, siendo esta última especialmente relevante puesto que es la que va a permitir, junto con la componente elementos geométricos, reconocer el cuadrado apoyado sobre una de sus vértices sin caer en la confusión de considerarlo un rombo. Asimismo, se asocia la componente de movimientos, al reconocer los giros como elementos que dejan invariante las propiedades métricas de las figuras.

A partir del tercer apartado se empiezan a poner en juego estrategias de generalización, puesto que el estudiante debe establecer relaciones para obtener una resolución eficiente. Por ejemplo, encontrar la relación existente entre el número de cuadrados de un día con el día anterior, así como la variación en el orden de las semillas (vértices) en cada una de las columnas y la suma de todos ellos con respecto al número de cuadrados. Es posible que en este apartado ya se plantee el término general y se particularice para el caso 100, lo que daría cuenta de un alto grado de generalización y aproximación al lenguaje algebraico.

Finalmente, en este apartado se pueden identificar algunas características del talento matemático relacionadas con la generalización:

- Localizar la clave de los problemas: Reconocer que al añadir una fila, se obtienen dos cuadrados pequeños, uno de los apoyados en el vértice y uno de los de mayor área. Así es posible ir contabilizando cada paso a partir del anterior. 
- Organizar los datos: clasificar los cuadrados obtenidos de cada tamaño y posición para llevar un conteo sistemático. Incluso utilizar una representación adecuada para ir recopilando la información

- Buscar relaciones con otras estructuras matemáticas: Relacionar el proceso con otros patrones conocidos y conectar el trabajo en las representaciones geométricas, numéricas y algebraicas.

Estas características pueden observarse si el estudiante muestra estrategias eficientes y justifica sus argumentos, especialmente cuando hace el salto de los patrones de cambio que reconoce en los primeros casos a la generalización expresada en lenguaje algebraico. Esto es lo que se pretende con el cuarto y último apartado, en el que se espera que el estudiante muestre que ha comprendido la relación que existe entre los días y el número de cuadrados con sus respectivas áreas. Para ello debe establecer la fórmula para cualquier número de días, lo que implica un uso eficiente del lenguaje algebraico (Soares, Blanton y Kaput, 2005).

\section{Tarea 2: Pintando Cubos y Cubitos}

En esta tarea se ponen en mayor medida en juego las componentes del sentido espacial y habilidades de visualización, aunque también requiere de las habilidades de conteo. El primer apartado se puede resolver de manera aritmética por lo que es el que menos relación guarda con el sentido espacial, aunque igualmente requiere de representaciones mentales.

Por otro lado, se ponen en juego componentes del sentido espacial como la de elementos geométricos, ya que el estudiante debe conocer diferentes conceptos que se mencionan en el enunciado como cubo, cuadrado, entre otros, para poder construir las representaciones mentales de este y de las figuras que se forman. A partir de ello, todos los planteamientos y modificaciones que recree de las figuras en relación con el plano o el espacio serán mentales, entrando en juego la componente de ubicación y movimientos especialmente asociada a la conservación de determinadas propiedades al girar la figura para describir las caras no visibles. En los demás apartados se pretende que el estudiante haga razonamientos geométricos poniendo en juego habilidades de visualización, tales como percepción figuracontexto al tener que aislar de su contexto figuras como cuadrado o cruz que aparecen 
distorsionadas por la superposición de otros elementos gráficos; conservación de la percepción, desde la cual reconocerá invariantes en los cubos pese a los diferentes giros que se les realiza gráfica o mentalmente; percepción de la posición en el espacio, desde la cual podrá asimilar las diferentes ubicaciones con respecto a sí misma que se le plantean en el enunciado (lateral izquierda y derecha, arriba, adelante); y por último percepción de relaciones espaciales, la cual le va a permitir identificar correctamente las relaciones que aparecen entre los cubitos situados simultáneamente en el espacio.

\section{ANEXO 4: SOLUCIÓN DE LA AUTORA}

\section{Sembrando semillas}

1) Tercer día:

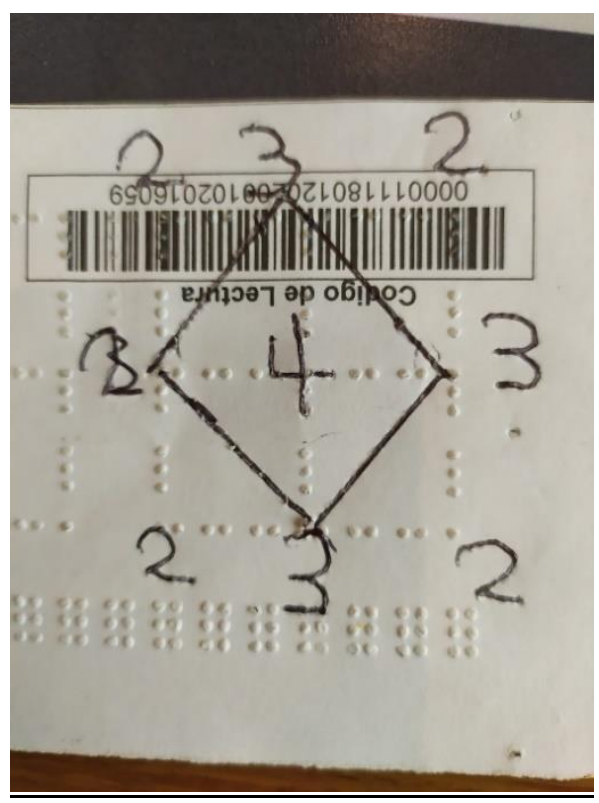

a) Podemos de la gráfica concluir fácilmente que tenemos un total de 6 cuadrados. Para calcular sus áreas utilizamos la fórmula $A=l^{2}$, y tenemos:

4 cuadrados pequeños de área $1\left(A=1^{2}\right)$, un cuadrado grande que encierra toda la figura de área $A=2^{2}=4$, y finalmente el cuadrado apoyado en una de sus vértices de área $A=$ 
$\sqrt{2} \times \sqrt{2}=2$. En este caso, para calcular uno de sus lados se utiliza el teorema de Pitágoras, aprovechando el triángulo que se forma con dos de los lados de uno de los cuadrados pequeños, correspondiendo a los catetos, y siendo la hipotenusa el lado de nuestro cuadrado diagonal.

b) De la figura podemos concluir también que la suma del orden de las semillas es 24. Como se observa en la gráfica, el orden de la semilla que queda en la mitad de la figura no se especifica, puesto que al tacto sería imposible discriminar el número. Por tanto, este se debe tener en cuenta mentalmente a la hora de hacer la suma.

2) Cuarto día:

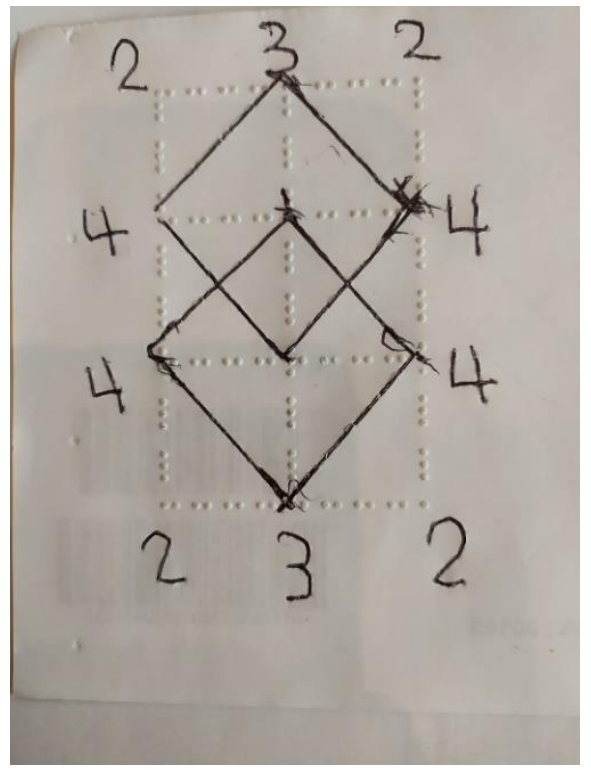

b) De la gráfica podemos concluir que hay un total de 10 cuadrados, de los cuales 6 tienen área igual a 1, 2 cuadrados un área igual a 4, y finalmente 2 cuadrados diagonales de área 2.

c) La suma del orden de las semillas es 40 . Nuevamente, no se puede especificar el orden de las semillas que quedan al interior de la figura puesto que es imposible diferenciar por saturación los números.

3) Día 100: Para responder esta pregunta considero que el camino más corto es directamente generalizar y luego remplazar por el número que me piden. Para ello, hago la gráfica del quinto 
día, con la intención de contabilizar el número de cuadrados y la suma del orden de las semillas para buscar un patrón en los datos que me permita hacer una generalización.

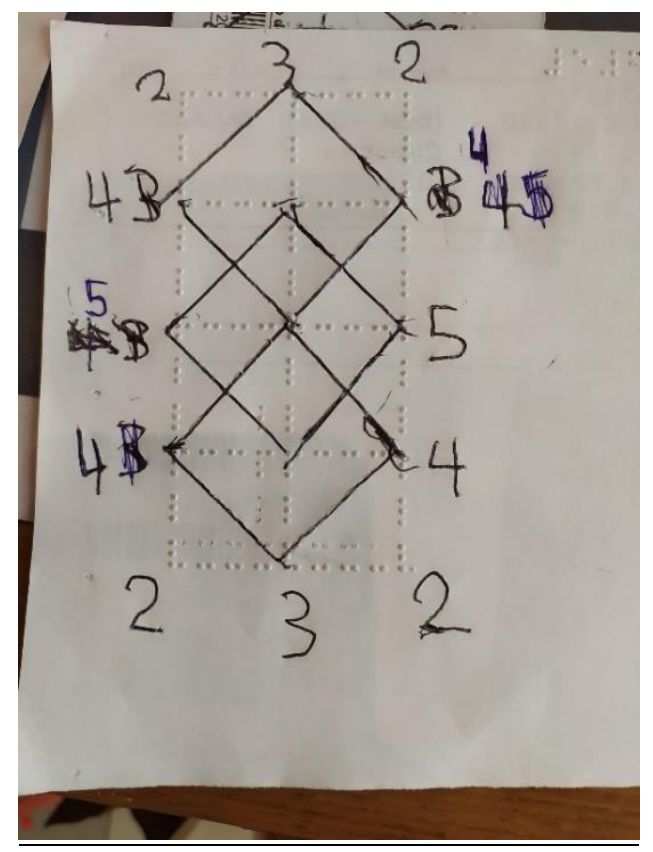

Podemos concluir de la gráfica que tenemos un total de 14 cuadrados y la suma del orden de las semillas es 56 .

De manera que para los días 3, 4 y 5 tenemos los siguientes datos:

\begin{tabular}{|l|l|l|}
\hline Día & Número de cuadrados & Suma del orden de las semillas \\
\hline 3 & 6 & 24 \\
\hline 4 & 10 & 40 \\
\hline 5 & 14 & 56 \\
\hline
\end{tabular}

Se observa que el número de cuadrados aumenta en un orden de 4 por día, comenzando por 6 . Por tanto, el número de cuadrados me queda representado por la fórmula:

$$
C=4 n-6
$$

Donde $C$ es el número de cuadrados y $n$ el número de día de siembra.

Por otro lado, para la suma del orden de las semillas se observa una relación entre el número de 
cuadrados y el orden, aumentando en un factor de 4. Por tanto, la suma del orden de las semillas me queda de la siguiente manera:

$$
S=4 C
$$

Donde $S$ es la suma del orden de las semillas y $C$ el número de cuadrados.

Así, podemos concluir que en el día 100 habrá un total de 394 cuadrados y la suma del orden de las semillas será 1576 .

Las áreas de estos cuadrados pueden calcularse teniendo en cuenta los datos obtenidos anteriormente, en los que se observa un patrón en la cantidad de cuadrados que se crea por cada área. Por ejemplo, vemos que la cantidad de cuadrados diagonales de área 2 es igual a la cantidad de cuadrados de área 4, y que además van aumentando de a 1 por cada día de siembra que transcurre. Podemos concluir fácilmente que restando 2 al número del día en que nos encontramos, obtenemos la cantidad de cuadrados con estas áreas. Por tanto, en el día 100 habrán 98 cuadrados de área 2 y 98 cuadrados de área 4. Esto conlleva a un total de 198 cuadrados de área 1.

4. día n:

a) La cantidad de cuadrados para el día n la podemos encontrar con la fórmula anterior. Sus áreas, de acuerdo con lo especificado en el punto anterior, las podremos hallar de la siguiente manera:

Para el caso de los cuadrados de área 2 y 4, tendríamos:

$C_{2,4}=n-2$

Donde $C_{2,4}$ son los cuadrados de área 2 y 4 (habrá la misma cantidad de cada uno) y n el número de días.

Para el caso de los cuadrados de área 1, teniendo en cuenta la fórmula para la cantidad total de cuadrados, bastará con realizar una resta entre ambos resultados para llegar a que dichas áreas las podremos encontrar con la fórmula:

$C_{1=} 2 n-2$

Donde $C_{1}$ son los cuadrados de área 1 y n el número de días.

d) La suma del orden de las semillas la podemos encontrar con la fórmula mencionada en el apartado anterior. 


\section{Pintando cubitos}

1) En el cubo inicial tenemos un total de 27 cubos. Al suprimir la parte que se aprecia en la segunda imagen, quedo con un total de 19 cubos, de los cuales 3 van a tener cuatro caras pintadas, 10 tres caras pintadas, de los cuales 6 coinciden en la forma, es decir, que tienen pintadas dos caras paralelas (las caras de adelante y atrás) y una perpendicular a ellas (la cara de arriba); mientras que 4 de ellos (los de las esquinas) las caras pintadas son perpendiculares entre sí (la cara de arriba, delante e izquierda); y finalmente 6 dos caras pintadas, donde 3 de ellos tienen caras paralelas pintadas (arriba y abajo) y los otros caras perpendiculares (arriba y delante).

Partiendo de que para un total de 54 caras se tuvieron que utilizar 9 botes de pintura, tenemos un total de 6 caras por cada bote de pintura. Creo entonces que se podrían disponer en fila un total de 15 cubos como máximo de la siguiente manera:

Ubico primero y de manera consecutiva dos de los tres cubitos con las cuatro caras pintadas, haciendo que una de las caras blancas quede apoyada en la superficie mientras que la otra coincida con la cara blanca del siguiente cubito, puesto en igual disposición. A continuación, agregaría 6 de los 10 cubitos que tienen 3 caras pintadas, de manera que una de las caras blancas quede apoyada sobre la superficie, la otra cara blanca coincida con la cara blanca del cubo anterior (en el caso del primero coincidiendo con una gris de los cubitos con cuatro caras pintadas) y así sucesivamente. Hasta este punto todas las caras visibles estarían pintadas.

A continuación, agregaría los cuatro cubos restantes con las tres caras pintadas, de manera que una de las caras blancas quede apoyada en la superficie, la otra cara blanca coincida con el cubo anterior y solo me quedaría una expuesta que se debe pintar, en la parte trasera de la fila. Posteriormente agregaría dos de los cubitos con dos caras perpendiculares pintadas, de manera que una de las caras blancas quede apoyada en la superficie, otra cara blanca coincida con el cubito anterior y la cara blanca expuesta quede también en la parte trasera de la fila. Para completar agregaría el cubito con cuatro caras pintadas que me quedaba en la misma disposición que los iniciales, cerrando la fila. De esta manera solo tendría que pintar seis caras. 
Nota: la descripción de las caras pintadas de los cubitos (arriba, delante, izquierda, etc.) se hace siempre desde la perspectiva de tomar el cubito de manera que una de las caras pintadas quede hacia arriba y la otra adelante con respecto a mí misma.

2) En este caso contamos con un total de 27 cubos, y su distribución con respecto a la cantidad de caras pintadas es la siguiente:

\begin{tabular}{cc}
\hline $\begin{array}{c}\mathrm{N}^{\circ} \mathrm{de} \\
\text { cubitos }\end{array}$ & $\begin{array}{c}\text { total de caras } \\
\text { pintadas }\end{array}$ \\
\hline 8 & 3 \\
12 & 2 \\
6 & 1 \\
1 & 0 \\
\hline
\end{tabular}

Para construir el cuadrado $5 \times 5$ necesitaremos un total de 16 cubitos, y para garantizar que pintemos el menor número de caras posibles en la figura resultante, debemos aprovechar aquellos que tengan un número mayor de caras pintadas.

Para esto los dispondremos de la siguiente manera:

En las esquinas del cuadrado ubicaremos cuatro de los ocho cubitos que tienen tres caras pintadas, de manera que una cara blanca quede apoyada en la superficie, y las otras dos queden hacia la parte interna de la figura que estamos formando, de esta manera conseguiríamos que las caras pintadas queden expuestas. Tres de los cuatro cubitos restantes los usaríamos para rellenar uno de los lados, con una de las caras blancas apoyada en la superficie y otra cara blanca coincidiendo con el cubito anterior. En este caso hay una cara blanca que nos quedará expuesta y una pintada que no podremos aprovechar ya que quedará en la parte interna de la figura. Para rellenar el resto del cuadro utilizaríamos ocho de los cubitos con dos caras pintadas, aprovechando que estas están ubicadas de manera perpendicular y los ubicaríamos de manera que una de las caras blancas quede apoyada en la superficie, las otras caras blancas coincidiendo con los cubitos anterior y posterior y las caras pintadas queden expuestas, con lo cual solo nos quedaría una cara expuesta para pintar por cada uno. Con esta construcción debemos pintar un total de 12 caras.

3) Para formar la cruz necesitaremos un total de cinco cubitos. Para esto aprovecharemos los cuatro cubitos restantes con dos caras pintadas y uno de los que tiene una sola pintada, el cual 
ubicaremos en la mitad con la cara pintada hacia arriba. Los otros cuatro cubitos los ubicaremos a su alrededor haciendo que las caras pintadas perpendiculares queden expuestas también, con lo cual solo tendríamos una cara expuesta por pintar de cada una. En total cuatro caras por pintar. 